Article

\title{
Post-Translational Modification Analysis of VDAC1 in ALS-SOD1 Model Cells Reveals Specific Asparagine and Glutamine Deamidation
}

\author{
Maria Gaetana Giovanna Pittalà ${ }^{1}$, Simona Reina ${ }^{1,2}$, Salvatore Antonio Maria Cubisino ${ }^{1}$, \\ Annamaria Cucina $^{3}\left(\mathbb{D}\right.$, Beatrice Formicola ${ }^{4}$, Vincenzo Cunsolo ${ }^{3}\left(\mathbb{D}\right.$, Salvatore Foti ${ }^{3}(\mathbb{D}$, \\ Rosaria Saletti ${ }^{3, *(1)}$ and Angela Messina ${ }^{1,2, *(1)}$ \\ 1 Department of Biological, Geological and Environmental Sciences, Molecular Biology Laboratory, \\ University of Catania, Via S. Sofia 64, 95123 Catania, Italy; marinella.pitt@virgilio.it (M.G.G.P.); \\ simona.reina@unict.it (S.R.); salvatore.cubisino@phd.unict.it (S.A.M.C.) \\ 2 we.MitoBiotech.srl, c.so Italia 172, 95129 Catania, Italy \\ 3 Department of Chemical Sciences, Organic Mass Spectrometry Laboratory, University of Catania, \\ Via S. Sofia 64, 95123 Catania, Italy; annamaria.cucina@phd.unict.it (A.C.); vcunsolo@unict.it (V.C.); \\ sfoti@unict.it (S.F.) \\ 4 School of Medicine \& Surgery, Nanomedicine Center NANOMIB, University of Milano-Bicocca, \\ 20900 Monza, Italy; b.formicola@campus.unimib.it \\ * Correspondence: rsaletti@unict.it (R.S.); mess@unict.it (A.M.); \\ Tel.: +39-095-7385026 (R.S.); +39-095-7384231 (A.M.)
}

Received: 28 September 2020; Accepted: 28 November 2020; Published: 2 December 2020

\begin{abstract}
Mitochondria from affected tissues of amyotrophic lateral sclerosis (ALS) patients show morphological and biochemical abnormalities. Mitochondrial dysfunction causes oxidative damage and the accumulation of ROS, and represents one of the major triggers of selective death of motor neurons in ALS. We aimed to assess whether oxidative stress in ALS induces post-translational modifications (PTMs) in VDAC1, the main protein of the outer mitochondrial membrane and known to interact with SOD1 mutants related to ALS. In this work, specific PTMs of the VDAC1 protein purified by hydroxyapatite from mitochondria of a NSC34 cell line expressing human SOD1G93A, a suitable ALS motor neuron model, were analyzed by tryptic and chymotryptic proteolysis and UHPLC/High-Resolution ESI-MS/MS. We found selective deamidations of asparagine and glutamine of VDAC1 in ALS-related NSC34-SOD1G93A cells but not in NSC34-SOD1WT or NSC34 cells. In addition, we identified differences in the over-oxidation of methionine and cysteines between VDAC1 purified from ALS model or non-ALS NSC34 cells. The specific range of PTMs identified exclusively in VDAC1 from NSC34-SOD1G93A cells but not from NSC34 control lines, suggests the appearance of important changes to the structure of the VDAC1 channel and therefore to the bioenergetics metabolism of ALS motor neurons. Data are available via ProteomeXchange with identifier $<$ PXD022598 $>$.
\end{abstract}

Keywords: deamidation; amyotrophic lateral sclerosis; voltage dependent anion channel; post-translational modifications; mitochondria; ROS; mass spectrometry analysis; Orbitrap fusion tribrid; neurodegeneration; SOD1

\section{Introduction}

Amyotrophic lateral sclerosis (ALS) is a devastating neurodegenerative disease caused by progressive degeneration of the motor neurons in the brainstem and spinal cord that leads patients to death by respiratory paralysis within $2-5$ years of onset [1]. While about $10 \%$ of ALS cases are 
associated with genetic defects, $90 \%$ of ALS cases are sporadic. Several genetic risk factors are also implicated in sporadic ALS (sALS) [2].

Oxidative stress-induced damage is a major mechanism in the ALS pathophysiology and can result from an imbalance between free radical production and degradation. Free radicals, such as reactive oxygen species (ROS) and reactive nitrogen species (RNS), are generated from various cell sources. Mitochondria are the main fount of ROS, while a smaller proportion of ROS and RNS is produced by non-mitochondrial oxidative enzymes [3]. Interestingly, non-mitochondrial ROS usually function as signaling molecules and are seldom involved in pathophysiological processes [4]. However, ROS produced through Nox enzymes have been implicated in ALS pathogenesis [5]. Free radicals cause oxidative damage to lipids, proteins, and nucleic acids contributing thus to trigger or amplify the pathological mechanisms related to ALS [6]. Therefore, mitochondrial dysfunction is both the main contributor to oxidative stress and its main consequence.

The $\mathrm{Cu} / \mathrm{Zn}$ superoxide dismutase (SOD1) associates with about $20 \%$ of familial ALS (fALS) cases and over 180 mutant forms of enzymatically active or inactive SOD1 have been characterized in humans (http://alsod.iop.kcl.ac.uk) [7]. In affected tissues, toxic effects of SOD1 mutants are related to the formation of misfolded SOD1 aggregates upon the mitochondrial surface, leading to morphological degeneration and malfunctioning of the organelle $[8,9]$.

In the spinal cord from ALS patients, voltage dependent anion selective channel isoform 1 (VDAC1) represents the docking site on the outer mitochondrial membrane for ALS-linked SOD1 mutants $[10,11]$.

VDAC1 is the most abundant protein of the outer mitochondrial membrane and is evolutionary preserved from yeast to man [12-14]. As a voltage-dependent anionic channel, it carries ATP, ions, and other small metabolites. It is responsible for metabolic exchanges to and from the mitochondrion, thus controlling cell metabolism and mitochondrial function. VDAC1 also acts as a scaffold for important molecules, such as hexokinase and proteins from the Bcl2 family which regulate metabolism and apoptosis. Apoptotic stimuli also induce VDAC1 oligomerization that leads to mitochondrial permeability and apoptosis [15]. Therefore, due to its important role, dysfunction of the VDAC channel can lead to various diseases, such as cancer and neurodegenerative diseases like Parkinson's disease, Alzheimer's disease, and ALS [16,17].

In ALS, the VDAC1-SOD1 mutant interaction strongly affects the functional properties of VDAC1 channel suggesting a role in the impairment of the bioenergetics metabolism and oxidative stress of ALS motor neurons [10]. It is also known that low levels of hexokinase I (HK1) in the spinal cord make motor neurons more susceptible to ALS in comparison to other tissues. In particular, this reduction of HK1 levels increases the availability of VDAC1 to interact with mutant SOD1, thereby facilitating mitochondrial dysfunction and cell death [10].

Protein-protein interactions (PPI) at the surface of mitochondria are an emerging novelty nowadays, but still few information is available. The mitochondria-associated proteins interact with the organelle orchestrating its response in order to maintain proper cellular function. In fact, alterations in selective PPIs at the mitochondrial surface are the result of pathological associations that drive the progression of neurodegenerative disorders [18]. Protein PTMs guide the cellular response to specific insults, distinguishing toxic PTMs (e.g., oxidations) and protective PTMs (e.g., cysteinylation); high levels of toxic changes or a varied set of PTMs are related to disease conditions.

Under physiological conditions, VDAC1 presents several post-translational changes (phosphorylation [19], acetylation [20], tyrosine nitration [21] and oxidation of cysteine and methionine) whose role in protein activity has only been partially clarified [22-24]. Moreover, VDAC1, like other mitochondrial proteins in the outer membrane, is a target for Parkin-mediated ubiquitination [25]. Ubiquitination, like phosphorylation and acetylation, is a reversible modification that allows the selection of dysfunctional mitochondria for clearance and regulates quality control pathways.

Recent advances in the study of molecular markers of ageing, hypoxia, and age-related neurodegenerative diseases have highlighted the important role of protein deamidation. As of today, no one studied possible deamidation of the VDAC channel. 
The abnormal accumulation of misfolded proteins and dysfunctional mitochondria is a distinctive feature of ALS and many neurodegenerative diseases [26]. In addition, mitochondrial proteins undergo further PTMs in response to both physiological and pathological cell signals. It is known that PTMs influence the activity of the VDAC channel and thus the mitochondrial function and its fate $[19,27]$. For example, cysteines undergo reversible and irreversible redox reactions by ROS and are important for the stabilization of the VDAC structure [22,28].

In this work, by using a high-resolution mass spectrometry analysis we identified non-reversible post-translational changes in VDAC1 that may be involved in its specific interaction with ALS-related SOD1 mutants. Our findings allow us to hypothesize its further role in the disease and as a marker for irreparably damaged mitochondria.

\section{Materials and Methods}

\subsection{Chemicals}

All chemicals were of the highest purity commercially available and were used without further purification. Ammonium bicarbonate, calcium chloride, phosphate-buffered saline (PBS), Tris- $\mathrm{HCl}$, Triton X-100, sucrose, mannitol, ethylene glycol tetraacetic acid (EGTA), ethylenediaminetetraacetic acid (EDTA), formic acid (FA), dithiothreitol (DTT) and iodoacetamide (IAA) were obtained from Sigma-Aldrich (Milan, Italy). High-glucose DMEM (Dulbecco's Modified Eagle Medium) and fetal bovine serum (FBS) were obtained from Gibco-Thermo Fisher Scientific (Milan, Italy). DMEM F12 and tetracycline-free FBS were obtained from Euro Clone. G418 and Doxycycline were obtained from Carlo Erba and Sigma-Aldrich (Milan, Italy), respectively. Trypsin/EDTA (for cell cultures) and penicillin-streptomycin (P/S) were purchased from Invitrogen. All the other stock solutions for cell culturewere from Euroclone (Milan, Italy). Modified porcine trypsin and chymotrypsin were purchased from Promega (Milan, Italy). Water and acetonitrile (OPTIMA ${ }^{\circledR}$ LC/MS grade) for LC/MS analyses were provided from Fisher Scientific (Milan, Italy).

\subsection{NSC34 Cell Lines}

The mouse motor neuron-like NSC34 cell line were from CELLutions Biosystem Inc., Burlington, ON, Canada) and NSC34 cells stably transfected with pTet-ON plasmid (Clontech, Mountain View, CA, USA) harboring sequences encoding SOD1 wt (NSC34-SOD1WT) or G93A (NSC34-SOD1G93A) were used as non-ALS motor neuron line and ALS motor neuron line, respectively [9]. Cell maintenance, induction, and transfection condition were as in Magrì et al., 2016 [10].

\subsection{Extraction of Mitochondrial Proteins from NSC34 Cells under Reducing Condition}

NSC34, NSC34-SOD1WT and NSC34-SOD1G93A cell lines were cultured in monolayer $75 \mathrm{~cm}^{2}$ tissue culture flask) until 75\% confluence. For mitochondria preparation about 80 million cells/culture were used; NSC34 cells were harvested by trypsin with $0.25 \%$ EDTA and washed with PBS three times before disruption. Every PBS wash was eliminated by centrifugation at $1500 \times g$ for 5 min at $4{ }^{\circ} \mathrm{C}$. Purification of mitochondria from NSC34-SOD1WT and NSC34-SOD1G93A cell lines was carried out $48 \mathrm{~h}$ after doxycycline induction of human SOD1 protein expression.

The total cell pellet obtained was resuspended in $1 \mathrm{~mL}$ of hypotonic buffer $(200 \mathrm{mM}$ mannitol, $70 \mathrm{mM}$ sucrose, $10 \mathrm{mM}$ HEPES $\mathrm{pH}$ 7.5, $1 \mathrm{mM}$ EGTA pH 8.0). The cells were incubated in ice for $10 \mathrm{~min}$ and then lysed. The lysate obtained was centrifuged $\left(700 \times g\right.$ for $25 \mathrm{~min}$ at $\left.4{ }^{\circ} \mathrm{C}\right)$ to eliminate the non-lysed cells and the nuclei. To increase the yield, after recovering the supernatant, the pellet containing the mitochondria was suspended in hypotonic buffer. Again, the suspension was first lysed and then centrifuged $\left(700 \times g\right.$ for $25 \mathrm{~min}$ at $\left.4{ }^{\circ} \mathrm{C}\right)$.

The resulting supernatants from the two centrifugations were combined and centrifuged at higher speed $\left(7000 \times g\right.$ for $15 \mathrm{~min}$ at $\left.4{ }^{\circ} \mathrm{C}\right)$. The supernatant, containing the cytoplasmic fraction, was removed while the pellet was washed with hypotonic buffer. 
The suspension was then centrifuged at high speed $\left(7000 \times g\right.$ for $15 \mathrm{~min}$ at $\left.4{ }^{\circ} \mathrm{C}\right)$ and at the end, after removing the supernatant, the pellet containing the mitochondria, was resuspended in $500 \mu \mathrm{L}$ of hypotonic buffer and stored at $4{ }^{\circ} \mathrm{C}$.

The total yield (in $500 \mu \mathrm{L}$ of hypotonic buffer) was determined by Bicinchoninic Acid Protein Assay (BCA method) resulting in $0.474 \mathrm{mg}, 0.524 \mathrm{mg}, 0.628 \mathrm{mg}$ for NSC34, NSC34-SOD1WT, and NSC34-SOD1G93A, respectively. The hypotonic buffer was then removed by centrifugation $\left(10,000 \times \mathrm{g}\right.$ for $20 \mathrm{~min}$ at $\left.4{ }^{\circ} \mathrm{C}\right)$. Reduction/alkylation was carried on before VDACs purification to avoid any possible artifact due to air exposure. $0.237 \mathrm{mg}, 0.262 \mathrm{mg}$ and $0.314 \mathrm{mg}$ of protein from intact mitochondria purified from NSC34, NSC34-SOD1WT and NSC34-SOD1G93A, respectively, were incubated for $3 \mathrm{~h}$ at $4{ }^{\circ} \mathrm{C}$ in $1 \mathrm{~mL}$ of Tris- $\mathrm{HCl} 10 \mathrm{mM}(\mathrm{pH} 8.3$ ) containing $0.00474 \mathrm{mmol}, 0.00524$ mmol and $0.00628 \mathrm{mmol}$ of DTT for each cell line: this corresponds to an excess of 50:1 (mol/mol) over the estimated protein thiol groups. The temperature was kept at $4{ }^{\circ} \mathrm{C}$ to avoid possible reduction of methionine sulfoxide to methionine by methionine sulfoxide reductase. The alkylation was performed by the addition of IAA at the 2:1 M ratio over DTT for $1 \mathrm{~h}$ in the dark at $25^{\circ} \mathrm{C}$. Mixture was centrifuged for $30 \mathrm{~min}$ at $10,000 \times \mathrm{g}$ at $4{ }^{\circ} \mathrm{C}$ and the pellet was stored at $-80{ }^{\circ} \mathrm{C}$ until further use.

Reduced and alkylated intact mitochondria were lysed in buffer A (10 mM TrisHCl, 1 mM EDTA, $3 \%$ Triton X-100, $\mathrm{pH} 7.0$ ) in ratio 5:1 (mitochondria $\mathrm{mg} / \mathrm{buffer}$ volume $\mathrm{mL}$ ) [29] for $30 \mathrm{~min}$ on ice and centrifuged at $17,400 \times g$ for $30 \mathrm{~min}$ at $4{ }^{\circ} \mathrm{C}$. The supernatant containing mitochondrial proteins was subsequently loaded onto a homemade glass column $5 \times 80 \mathrm{~mm}$, packed with $0.6 \mathrm{~g}$ of dry hydroxyapatite (Bio-Gel HTP, Biorad). The column was eluted with buffer A at $4{ }^{\circ} \mathrm{C}$ and fractions of $500 \mu \mathrm{L}$ were collected and tested for protein content by a fluorometer assay (Invitrogen Qubit ${ }^{\mathrm{TM}}$ Protein Assay kit, ThermoFisher Scientific, Milan, Italy). Fractions containing proteins were pooled and dried under vacuum. The hydroxyapatite eluate was divided into two aliquots, which were reduced to less than $100 \mu \mathrm{L}$ and purified from non-protein contaminating molecules with the PlusOne 2-D Clean-Up kit (GE Healthcare Life Sciences, Milan, Italy) according to the manufacturer's instructions. The desalted protein pellet was suspended in $100 \mu \mathrm{L}$ of $50 \mathrm{mM}$ ammonium bicarbonate ( $\mathrm{pH}$ 8.3) and incubated at $4{ }^{\circ} \mathrm{C}$ for $15 \mathrm{~min}$. Next, $100 \mu \mathrm{L}$ of $0.2 \%$ RapiGest SF (Waters, Milan, Italy) in $50 \mathrm{mM}$ ammonium bicarbonate were added and the samples were incubated at $4{ }^{\circ} \mathrm{C}$ for $30 \mathrm{~min}$. Another aliquot of desalted protein pellet was suspended in $100 \mu \mathrm{L}$ of $100 \mathrm{mM}$ Tris- $\mathrm{HCl}, 10 \mathrm{mM}$ calcium chloride $(\mathrm{pH} 8.0)$ and incubated at $4{ }^{\circ} \mathrm{C}$ for $15 \mathrm{~min}$. Next, $100 \mu \mathrm{L}$ of $0.2 \%$ RapiGest SF in $100 \mathrm{mM}$ Tris- $\mathrm{HCl}$ and $10 \mathrm{mM}$ calcium chloride were added, and the samples were kept at $4{ }^{\circ} \mathrm{C}$ for $30 \mathrm{~min}$. For each fraction, the recovered protein amount was determined in $100 \mu \mathrm{g}$ by using a fluorometer assay. Reduced and alkylated proteins were then subjected separately to digestion using modified porcine trypsin and chymotrypsin, respectively. Tryptic digestion was carried out at an enzyme-substrate ratio of $1: 50$ at $37{ }^{\circ} \mathrm{C}$ for $4 \mathrm{~h}$. Chymotryptic digestion was performed in Tris- $\mathrm{HCl} 100 \mathrm{mM}, 10 \mathrm{mM}$ calcium chloride (pH 8.0) at an enzyme-substrate ratio of 1:20, overnight at $25^{\circ} \mathrm{C}$.

\subsection{Liquid Chromatography and Tandem Mass Spectrometry (LC-MS/MS) Analysis}

Mass spectrometry data were acquired in triplicate for each sample assayed on an Orbitrap Fusion Tribrid (Q-OT-qIT) mass spectrometer (ThermoFisher Scientific, Bremen, Germany) equipped with a ThermoFisher Scientific Dionex UltiMate 3000 RSLCnano system (Sunnyvale, CA, USA), to assess the reproducibility of the available MS data. Samples obtained by in-solution tryptic and chymotryptic digestion were reconstituted in $30 \mu \mathrm{L}$ of $5 \%$ FA aqueous solution and $1 \mu \mathrm{L}$ was loaded onto an Acclaim ${ }^{\circledR}$ Nano Trap C18 column $(100 \mu \mathrm{m}$ i.d. $\times 2 \mathrm{~cm}, 5 \mu \mathrm{m}$ particle size, $100 \AA)$. After washing the trapping column with solvent $\mathrm{A}\left(\mathrm{H}_{2} \mathrm{O}+0.1 \% \mathrm{FA}\right)$ for $3 \mathrm{~min}$ at a flow rate of $7 \mu \mathrm{L} / \mathrm{min}$, the peptides were eluted from the trapping column onto a PepMap ${ }^{\circledR}$ RSLC C18 EASY Spray, $75 \mu \mathrm{m} \times 50 \mathrm{~cm}, 2 \mu \mathrm{m}$, $100 \AA$ column and were separated by elution at a flow rate of $0.250 \mu \mathrm{L} / \mathrm{min}$, at $40{ }^{\circ} \mathrm{C}$, with a linear gradient of solvent $\mathrm{B}\left(\mathrm{CH}_{3} \mathrm{CN}+0.1 \% \mathrm{FA}\right)$ in $\mathrm{A}$ from $5 \%$ to $20 \%$ in $32 \mathrm{~min}$, followed by $20 \%$ to $40 \%$ in $30 \mathrm{~min}$, and $40 \%$ to $60 \%$ in $20 \mathrm{~min}$. Eluted peptides were ionized by a nanospray (Easy-spray ion source (ThermoFisher Scientific, Bremen, Germany), using a spray voltage of $1.7 \mathrm{kV}$ and introduced 
into the mass spectrometer through a heated ion transfer tube $\left(275^{\circ} \mathrm{C}\right)$. Survey scans of peptide precursors in the $m / z$ range 400-1600 were performed at a resolution of 120,000 (@200 m/z) with an AGC target for the Orbitrap survey of $4.0 \times 10^{5}$ and a maximum injection time of $50 \mathrm{~ms}$. Tandem MS was performed by isolation at 1.6 Th with the quadrupole, and high energy collisional dissociation (HCD) was performed in the Ion Routing Multipole (IRM), using a normalized collision energy of 35 and rapid scan MS analysis in the ion trap. Only those precursors with charge state 1-3 and intensity above the threshold of $5 \times 10^{3}$ were sampled for $\mathrm{MS}^{2}$. The dynamic exclusion duration was set to $60 \mathrm{~s}$ with a 10-ppm tolerance around the selected precursor and its isotopes. Monoisotopic precursor selection was turned on. AGC target and maximum injection time for MS/MS spectra were $1.0 \times 10^{4}$ and $100 \mathrm{ms,}$ respectively. The instrument was run in top speed mode with $3 \mathrm{~s}$ cycles, meaning the instrument would continuously perform $\mathrm{MS}^{2}$ events until the list of non-excluded precursors diminishes to zero or $3 \mathrm{~s}$, whichever is shorter. MS/MS spectral quality was enhanced enabling the parallelizable time option (i.e., by using all parallelizable time during full scan detection for MS/MS precursor injection and detection). Mass spectrometer calibration was performed using the Pierce ${ }^{\circledR}$ LTQ Velos ESI Positive Ion Calibration Solution (Thermo Fisher Scientific, Milan, Italy). MS data acquisition was performed using the Xcalibur v. 3.0.63 software (Thermo Fisher Scientific, Milan, Italy).

\subsection{Database Search}

LC-MS/MS data were processed by PEAKS de novo sequencing software (v. X, Bioinformatics Solutions Inc., Waterloo, ON, Canada). The data were searched against the 17,463 entries "Mus musculus" SwissProt database (release November 2019). The common Repository of Adventitious Proteins (c-RAP) contaminant database was included in the database search. Full tryptic or chymotrypsin peptides with a maximum of 3 missed cleavage sites were subjected to a bioinformatic search. Cysteine carboxyamidomethylation was set as the fixed modification, whereas oxidation of methionine, trioxidation and succination of cysteine, phosphorylation of serine, threonine and tyrosine, ubiquitin $(\mathrm{m} / \mathrm{z} 114.0429)$ and ubiquitination $(\mathrm{m} / \mathrm{z} 383.2281)$ of lysine, transformation of $N$-terminal glutamine and $\mathrm{N}$-terminal glutamic acid residues in the form of pyroglutamic acid and $\mathrm{N}$-terminal protein acetylation were included as variable modifications. The precursor mass tolerance threshold was 10 ppm, and the maximum fragment mass error was set to 0.6 Da. Peptide spectral matches (PSM) were validated using Target Decoy PSM Validator node based on q-values at a $0.1 \%$ False Discovery Rate (FDR). A protein was considered identified with a minimum of two peptides of which at least one had to be "unique". Proteins containing the same peptides which could not be differentiated based on MS/MS analysis alone were grouped to satisfy the principles of parsimony. Finally, all the protein hits obtained were processed by using the InChorus function of PEAKS. This tool combines the database search results of PEAKS software with those obtained by the Mascot search engine with the aim not only to increase the coverage but also the confidence since the engines use independent algorithms and therefore the results confirm each other.

The raw data were also processed by MaxQuant 1.6.3.4 to further investigate deamidation. To this end, MaxQuant gives information about intensity of peptides in both unmodified and modified forms, allowing for an estimation of the deamidation ratio. The main parameters of the previous search were maintained: database, contaminant database, type of digestion, fixed and variable modifications. The principles of parsimony were still applied. Match type was "match from and to". The decoy mode was "revert". PSM, Protein and Site decoy fraction FDR were set at 0.01 as it was the threshold for peptide and protein identifications. All the other parameters were set as default.

\subsubsection{Identification of Deamidation Sites on VDAC1}

An estimation of the percentage of deamidation in VDAC1 for each cell line was calculated with the aid of a freely available command-line script for Python 2.x (https://github.com/dblyon/deamidation), which uses the MaxQuant "evidence.txt" file. It has to be considered that the method is intended for comparative purposes and not as an absolute measure of deamidation. 
MaxQuant's "evidence.txt" file was used to calculate separate deamidation rates for Asparagine $(\mathrm{N})$ and Glutamine $(\mathrm{Q})$. The fraction of num_N (number of Asparagines) to num_N-2-D (number of deamidated Asparagines) and the fraction num_Q (number of Glutamines) to num_Q-2-E (number of deamidated Glutamines) were calculated for each peptide-to-spectrum match (PSM). The values obtained were termed respectively ratio_N-2-D and ratio_Q-2-E. The ratio_N-2-D or ratio_Q-2-E was multiplied for the "intensity" of the PTM, the values were summed, and the result divided by the total sum of all intensity values of the respective unmodified peptide sequence, obtaining a deamidation rate between 0 and 1 for each unique peptide sequence and charge state. For each peptide was calculated an average deamidation rate for Asparagine and Glutamine. The deamidation rates were averaged per sample. The latter set of values was sampled with replacement (bootstrapped) 1000 times. The mean, the standard deviation, and the $95 \%$ confidence intervals were calculated in order to achieve an estimate of the error of the calculation [30].

The program generates four delimited text files as output: (1) Deamidation.txt (Raw Files, deamidation for $\mathrm{N}$ and $\mathrm{Q}$, as mean, standard deviation, 95\% confidence lower and upper limit); (2) Number_of_Peptides_per_RawFile.txt; (3) Bootstrapped_values.txt (all the deamidation percentages calculated by e.g., 1000 bootstrap iterations, which are subsequently used to calculate the mean, std, and CI for shown in "Deamidation.txt"); (4) Protein_deamidation.txt (deamidation on the protein level).

\subsubsection{Semi-Quantitative Analysis}

A semi-quantitative analysis was performed by selecting the Fast LFQ (label-free quantification) option in MaxQuant 1.6.3.4. As recommended by Cox J. [31], "unique plus razor peptides" were included in the quantification. Razor-peptides are non-unique peptides assigned according to Occam's razor principle. Only unmodified peptides were used for quantification. "Advanced ratio estimation", "stabilize large LFQ ratios", "require MS/MS for comparisons" and "advanced site intensities" were selected. The runs were automatically aligned.

\subsection{Modelling and Bioinformatics Analysis}

Computational representation of the structures of VDAC1 N37D, N106D, N207D, N214D, N239D, 5Asn/Asp and 5Asn/Asp-2Gln/Glu were obtained by MODELLER v9.24 software (Webb \& Sali, 2016) using the crystallographic structure of mouse VDAC1 WT (PDB: 3EMN) as template. Mutations were introduced by substitution of the selected amino acid residue(s) in the FASTA sequence. The same software was used for the evaluation of the energetic score associated with each structure. Graphical representation was obtained by using VMD—Visual Molecular Dynamic software (available at: https://www.ks.uiuc.edu/Research/vmd/). The root-means-square deviation (RMSD) analysis and the Ramachandran plots (RPs) were obtained by using specific tools in the VMD software. The number of $\alpha$-helix, $\beta$-strand or unstructured domains was then analyzed and expressed as a percentage of the total.

\section{Results}

Our study was mainly focused on the identification of enzymatic and non-enzymatic PTMs in the VDAC1 protein from an established ALS mouse motor neuron-like cell line, especially considering the changes induced by oxidative stress typical of neurons affected by the disease.

Exactly, we searched, by mass spectrometry analysis, PTMs as oxidation and succination of cysteine residues, oxidation of methionine residue, phosphorylation of serine, tyrosine and threonine residues, ubiquitin and ubiquitination of lysine residues, and deamidation of asparagine and glutamine residues (Supplementary Figure S1).

To exclude the possibility that any unspecific and undesired oxidation could arise from the sample purification procedure, the reduction and alkylation of proteins were performed before VDACs purification. Hydroxyapatite (HTP) eluates of Triton X-100 extract were digested in-solution by trypsin and chymotrypsin and subsequently analysed in triplicate by liquid chromatography-mass 
spectrometry. In this experiment, every protein in the HTP eluate was digested, thus a very complex peptide mixture was produced. Irrespective of the cell line from which the protein was isolated, nUHPLC/nESI-MS/MS analysis of the in-solution tryptic and chymotryptic digest of VDAC1 allowed to ascertain that the $N$-terminal methionine reported in the SwissProt database sequence (Acc. N. Q60932) was missing in the mature protein (Figure 1) analogously to the rat and human VDAC1 isoform [22,28]. Combining the results obtained in the complementary tryptic and chymotryptic digestions of the three cellular lines, a coverage of $96.8 \%$ of VDAC1 sequence was obtained ( 273 out of 282 amino acid residues; Figure 1). The regions not covered correspond to short traits or single amino acids $\left(\mathrm{Thr}^{19}-\mathrm{Lys}^{20}, \mathrm{Leu}^{29}\right.$, $\mathrm{Arg}^{63}, \mathrm{Gly}^{220}$-Lys $^{224}$ ). MS analysis was also performed on VDAC1 samples purified from another series of NSC34, NSC34-SOD1WT, and NSC34-SOD1G93A cell cultures used in this work, in the same way as the first one. The data obtained were largely superimposable with the former (data not shown).

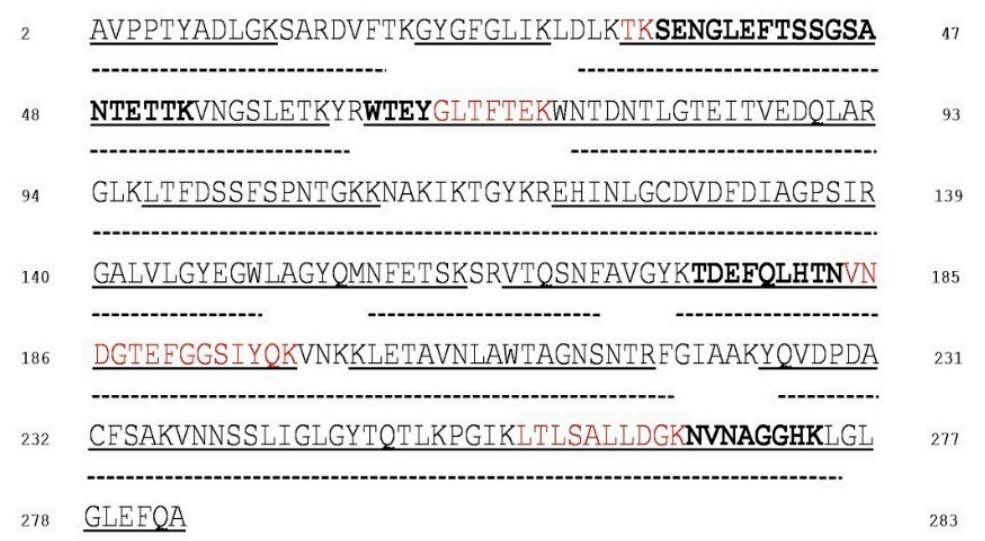

Figure 1. Sequence coverage map of VDAC1 from NSC34, NSC34-SOD1WT and NSC34-SOD1G93A cell lines obtained by tryptic and chymotryptic digestion. The solid line indicates sequence that was obtained from tryptic peptides; dotted lines: sequence obtained from chymotryptic peptides. Unique tryptic (indicated in bold) peptides originated by missed-cleavages were used to distinguish and cover sequences shared by isoforms. Sequences shared by more isoforms are reported in red. The numbering of the sequence considered the starting methionine residue, which is deleted during protein maturation.

The sequence of VDAC1 from Mus musculus contains one methionine in position 155, and two cysteines in position 127 and 232. It should be noted that the numeration adopted in the discussion starts from $\mathrm{Met}^{1}$, which is absent in the mature protein.

\subsection{Mass Spectrometry Analysis of VDAC1 from NSC34 Cell Line}

The mass spectrometry analysis was first performed on material obtained from NSC34 wild-type cells, to establish a reference pattern and to compare the results with those reported for other cell lines.

Met $^{155}$ was identified in the normal form (Supplementary Table S1, fragment 10), but also as Met sulfoxide and Met sulfone (Supplementary Table S3, fragments 2 and 3). Supplementary Figure S2 shows the full scan and fragment ion mass spectrum of the molecular ion of the peptide $\mathrm{G}^{140}$ ALVLGYEGWLAGYQMNFETSK ${ }^{161}$ with Met $^{155}$ oxidized to methionine sulfoxide. The full scan mass spectrum of the molecular ion of the same peptide with $\mathrm{Met}^{155}$ oxidized to methionine sulfone is reported in Figure S3. The MS/MS spectrum of Met sulfoxide presents the characteristic neutral loss of $64 \mathrm{Da}$ corresponding to the ejection of methanesulfenic acid from the side chain of MetO [32].

Although from these data a precise determination of the amount of Met, Met sulfoxide, and Met sulfone cannot be obtained, a rough estimation of their relative abundance can be derived from the comparison of the absolute intensities of the multiply charged molecular ions of the respective peptides. From these calculations, a ratio of about 5:1 MetO/Met and 0.1:1 $\mathrm{MetO}_{2} / \mathrm{Met}$ was found (Table S5). 
Regarding the oxidation state of cysteines, mass spectral analysis indicated that Cys ${ }^{232}$ was completely in the carboxyamidomethylated form (Supplementary Table S1, fragment 15), while Cys ${ }^{127}$ was exclusively in the oxidized form of sulfonic acid (Supplementary Figure S4 and Supplementary Table S3, fragment 1), thus reproducing the same data obtained with the homologous human isoform [31]. Chymotryptic digestion was also performed and the data obtained confirmed the complete trioxidation of $\mathrm{Cys}^{127}$ (Supplementary Table S4, fragment 1) and the total carboxyamidomethylation of Cys $^{232}$ (Supplementary Table S2, fragment 30).

\subsection{Mass Spectrometry Analysis of VDAC1 from NSC34-SOD1WT Cell Line}

In this section VDAC1 modifications found in NSC34 cells expressing a wt form of human SOD1 were analyzed. MS results indicate that the oxidation state of Met and Cys residues are very similar to the one reported for the same isoform from the NSC34 non transfected cells, discussed previously. In particular, in the tryptic digest Met ${ }^{155}$ was detected both in the normal form (Supplementary Table S6, fragment 10) and oxidized to sulfoxide and sulfone, (Supplementary Figures S5 and S6 and Table S8, fragments 2 and 3) with a ratio of about 3:1 and 0.1:1 MetO/Met and $\mathrm{MetO}_{2} / \mathrm{Met}$, respectively (Supplementary Table S10). In addition, Cys ${ }^{127}$ was detected only in the form of sulfonic acid (Supplementary Figure S7 and Table S8, fragment 1), whereas Cys ${ }^{232}$ was fully carboxyamidomethylated (Supplementary Table S6, fragment 15).

These results were again confirmed by the complementary chymotryptic digestion (Supplementary Table S9, fragment 1, and Table S7, fragments 36 and 37).

\subsection{Mass Spectrometry Analysis of VDAC1 from NSC34-SOD1G93A Cell Line}

In this section VDAC modifications found in NSC34 cells expressing the G93A mutated sequence of the human SOD1 were analyzed. MS analysis of tryptic and chymotryptic digest of VDAC1 from NSC34-SOD1G93A cell revealed the presence of $\mathrm{Cys}^{232}$ exclusively in the carboxyamidomethylated form (Supplementary Table S11, fragment 15; Table S12, fragment 25), and the partial oxidation of $\mathrm{Met}^{155}$ to methionine sulfoxide and sulfone (Supplementary Figures S8 and S9 and Table S13, fragments 2 and 3, respectively). In contrast to the results found in other cells, a higher amount of methionine sulfoxide and sulfone was observed (Ox/Red ratio 61:1 and 4.7:1, respectively; Table 1). Furthermore, peptides containing Cys ${ }^{127}$ residue in the carboxyamidomethylated form (Supplementary Table S11, fragment 9) and also oxidized to sulfonic acid were detected (Supplementary Figure S10 and Table S13, fragment 1) with a ratio of 24:1 (Table 1).

Table 1. Ratio of the absolute intensities of the molecular ions of the sulfur-containing tryptic peptides found in the analysis of VDAC1 from NSC34-SOD1G93A cells HTP-preparation reduced with DTT, carboxyamidomethylated and digested in-solution.

\begin{tabular}{|c|c|c|c|c|c|}
\hline $\begin{array}{l}\text { Technical } \\
\text { Replicate }\end{array}$ & Peptide & $\begin{array}{l}\text { Position in the } \\
\text { Sequence }\end{array}$ & $\begin{array}{c}\text { Measured } \\
\text { Monoisotopic } m / z\end{array}$ & $\begin{array}{l}\text { Absolute } \\
\text { Intensity }\end{array}$ & Ratio Ox/Red \\
\hline I & EHINLGCDVDFDIAGPSIR & \multirow{6}{*}{$121-139$} & $1059.9921(+2)$ & $8.2 \times 10^{5}$ & \multirow[b]{2}{*}{29.3} \\
\hline I & EHINLGCDVDFDIAGPSIR & & $710.0155(+3)$ & $2.8 \times 10^{4}$ & \\
\hline II & EHINLGCDVDFDIAGPSIR & & $1059.9915(+2)$ & $6.9 \times 10^{5}$ & \multirow{2}{*}{19.2} \\
\hline II & EHINLGCDVDFDIAGPSIR & & $710.0140(+3)$ & $3.6 \times 10^{4}$ & \\
\hline III & EHINLGCDVDFDIAGPSIR & & $1059.9928(+2)$ & $7.8 \times 10^{5}$ & \multirow{2}{*}{23.6} \\
\hline III & EHINLG $\bar{C} D V D F D I A G P S I R$ & & $710.0140(+3)$ & $3.3 \times 10^{4}$ & \\
\hline I & GALVLGYEGWLAGYQMNFETSK & \multirow{6}{*}{$140-161$} & $1225.5892(+2)$ & $4.5 \times 10^{6}$ & \multirow{2}{*}{60.0} \\
\hline I & GALVLGYEGWLAGYQMNNETSK & & $1217.5931(+2)$ & $7.5 \times 10^{4}$ & \\
\hline II & GALVLGYEGWLAGYQMNFETSK & & $1225.5897(+2)$ & $4.9 \times 10^{6}$ & \multirow{2}{*}{71.0} \\
\hline II & GALVLGYEGWLAGYQMNNETSK & & $1217.5913(+2)$ & $6.9 \times 10^{4}$ & \\
\hline III & GALVLGYEGWLAGYQMNFETSK & & $817.3946(+3)$ & $2.8 \times 10^{6}$ & \multirow{2}{*}{51.9} \\
\hline III & GALVLGYEGWLAGYQMNFETSK & & $812.0656(+3)$ & $5.4 \times 10^{4}$ & \\
\hline I & GALVLGYEGWLAGYQMNFETSK & \multirow{4}{*}{$140-161$} & $822.7261(+3)$ & $2.2 \times 10^{5}$ & \multirow{2}{*}{2.9} \\
\hline I & GALVLGYEGWLAGYQMNFETSK & & $1217.5931(+2)$ & $7.5 \times 10^{4}$ & \\
\hline II & GALVLGYEGWLAGYQMNFETSK & & $822.7269(+3)$ & $4.5 \times 10^{5}$ & \multirow[b]{2}{*}{6.5} \\
\hline II & GALVLGYEGWLAGYQMNFETSK & & $1217.5913(+2)$ & $6.9 \times 10^{4}$ & \\
\hline
\end{tabular}


Table 1. Cont.

\begin{tabular}{|c|c|c|c|c|c|}
\hline $\begin{array}{l}\text { Technical } \\
\text { Replicate }\end{array}$ & Peptide & $\begin{array}{l}\text { Position in the } \\
\text { Sequence }\end{array}$ & $\begin{array}{c}\text { Measured } \\
\text { Monoisotopic } m / z\end{array}$ & $\begin{array}{l}\text { Absolute } \\
\text { Intensity }\end{array}$ & Ratio Ox/Red \\
\hline III & GALVLGYEGWLAGYQMNFETSK & & $822.7277(+3)$ & $2.6 \times 10^{5}$ & \multirow{2}{*}{4.8} \\
\hline III & GALVLGYEGWLAGYQMNFETSK & & $812.0656(+3)$ & $5.4 \times 10^{4}$ & \\
\hline
\end{tabular}

\subsection{Post-Translational Modifications Found in VDAC1 HTP-Prepared from Various NSC34 Cell Lines}

3.4.1. Phosphorylation, Succination, Ubiquitin and Ubiquitination, and N-Terminal Acetylation

Mass spectral data were also analyzed to reveal the occurrence of serine, threonine, or tyrosine phosphorylation. In all the replicates of the three cellular lines, only Ser ${ }^{104}$ was observed to be phosphorylated (Supplementary Tables S14-S16), even if always in a low amount (Supplementary Tables S17-S19), as indicated in the corresponding MS/MS spectra, which show typical losses of phosphoric acid (P) from fragment ions $y$, in accord with previous reports $[33,34]$ (Supplementary Figures S11-S13).

The N-end $\mathrm{Ala}^{2}$ is only present in acetylated form in all the replicates of the three cell lines (Supplementary Figure S14 and Table S1, fragment 1; Figure S15 and Table S6, fragment 1; Figure S16 and Table S11, fragment 1 respectively). These results were confirmed by the analysis of the chymotryptic digest (Supplementary Table S2, fragments 1 and 2; Table S7, fragments 1 and 2; Table S12, fragment 1). Moreover, succinated cysteines were not found in VDAC1 isoforms from any kind of studied NSC34 cell, as well as no evidence of ubiquitin and ubiquitination was detected.

\subsubsection{Identification of VDAC1 Deamidation Sites from NSC34-SOD1G93A Cell Line}

Deamidations of specific residues of asparagine and glutamine were detected only in VDAC1 purified from NSC34-SOD1G93A cells. This result was confirmed in each replicate analyzed (Table S15). Exactly, five asparagines $\left(\mathrm{Asn}^{37}, \mathrm{Asn}^{106}, \mathrm{Asn}^{207}, \mathrm{Asn}^{214}\right.$, and $\mathrm{Asn}^{239}$, Supplementary Table S20, fragments 1, 2, 3, 5, 6, and 8, and Figure 2 and Figure S17-S21) were transformed to aspartate and two glutamines ( $\operatorname{Gln}^{166}$ and $\operatorname{Gln}^{226}$, Table S20, fragments 4 and 7, and Supplementary Figures S22 and S23) to glutamate.

In particular, Table 2 suggests that an appreciable amount of $\mathrm{Asn}^{207}$ is deamidated (ratio deam/norm 0.6), whereas deamidated $G \ln ^{166}$ and $G \ln ^{226}$ are visible in trace amounts (ratio deam/norm 0.002). Furthermore, for the other asparagines a ratio Asn-deamidated-to-Asp/Asn ranging from 0.01:1 to 0.04:1 was observed.

Table 2. Ratio of the absolute intensities of the molecular ions of tryptic peptides containing deamidated against not deamidated amino acids, found in the analysis of VDAC1 from NSC34-SOD1G93A cell HTP-preparation reduced with DTT, carboxyamidomethylated and digested in-solution.

\begin{tabular}{|c|c|c|c|c|}
\hline Peptide & $\begin{array}{l}\text { Position in the } \\
\text { Sequence }\end{array}$ & $\begin{array}{c}\text { Measured } \\
\text { Monoisotopic } m / z\end{array}$ & Absolute Intensity & Ratio Deam/Norm \\
\hline $\begin{array}{l}\text { TKSENGLEFTSSGSANTETTK } \\
\text { TKSENGLEFTSSGSANTETTK }\end{array}$ & $33-53$ & $\begin{array}{l}730.6730(+3) \\
730.3450(+3)\end{array}$ & $\begin{array}{l}6.3 \times 10^{6} \\
3.3 \times 10^{8}\end{array}$ & 0.02 \\
\hline $\begin{array}{l}\text { SENGLEFTSSGSANTETTK } \\
\text { SENGLEFTSSGSANTETTK }\end{array}$ & $35-53$ & $\begin{array}{l}654.2921(+3) \\
980.4425(+2)\end{array}$ & $\begin{array}{l}6.3 \times 10^{5} \\
1.4 \times 10^{8}\end{array}$ & 0.01 \\
\hline $\begin{array}{l}\text { LTFDSSFSPNTGKK } \\
\text { LTFDSSFSPNTGKK }\end{array}$ & 97-110 & $\begin{array}{l}510.5876(+3) \\
764.8857(+2)\end{array}$ & $\begin{array}{l}1.3 \times 10^{6} \\
9.9 \times 10^{7}\end{array}$ & 0.01 \\
\hline $\begin{array}{l}\text { VTQSNFAVGYK } \\
\text { VTQSNFAVGYK }\end{array}$ & $164-174$ & $\begin{array}{l}607.8062(+2) \\
607.3142(+2)\end{array}$ & $\begin{array}{l}1.4 \times 10^{6} \\
6.2 \times 10^{8}\end{array}$ & 0.002 \\
\hline
\end{tabular}


Table 2. Cont.

\begin{tabular}{|c|c|c|c|c|}
\hline Peptide & $\begin{array}{c}\text { Position in the } \\
\text { Sequence }\end{array}$ & $\begin{array}{c}\text { Measured } \\
\text { Monoisotopic } m / z\end{array}$ & Absolute Intensity & Ratio Deam/Norm \\
\hline KLETAVNLAWTAGNSNTR & \multirow{2}{*}{$201-218$} & $649.6692(+3)$ & $9.6 \times 10^{6}$ & \multirow{2}{*}{0.6} \\
\hline KLETAVNLAWTAGNSNTR & & $649.3412(+3)$ & $1.6 \times 10^{7}$ & \\
\hline LETAVNLAWTAGNSNTR & \multirow{2}{*}{$202-218$} & $909.9527(+2)$ & $6.8 \times 10^{5}$ & \multirow{2}{*}{0.04} \\
\hline LETAVNLAWTAGNSNTR & & $909.4607(+2)$ & $1.9 \times 10^{7}$ & \\
\hline YQVDPDACFSAK & \multirow{2}{*}{$225-236$} & $701.3032(+2)$ & $1.6 \times 10^{6}$ & \multirow{2}{*}{0.002} \\
\hline YQVDPDACFSAK & & $700.8112(+2)$ & $7.1 \times 10^{8}$ & \\
\hline VNNSSLIGLGYTQTLKPGIK & \multirow{2}{*}{$237-256$} & $702.0598(+3)$ & $2.4 \times 10^{6}$ & \multirow{2}{*}{0.03} \\
\hline VNNSSLIGLGYTQTLKPGIK & & $701.7318(+3)$ & $7.4 \times 10^{7}$ & \\
\hline
\end{tabular}

$C$ : cysteine carboxyamidomethylated; $\mathbf{N}$ : asparagine deamidated; $\mathbf{Q}:$ glutamine deamidated.
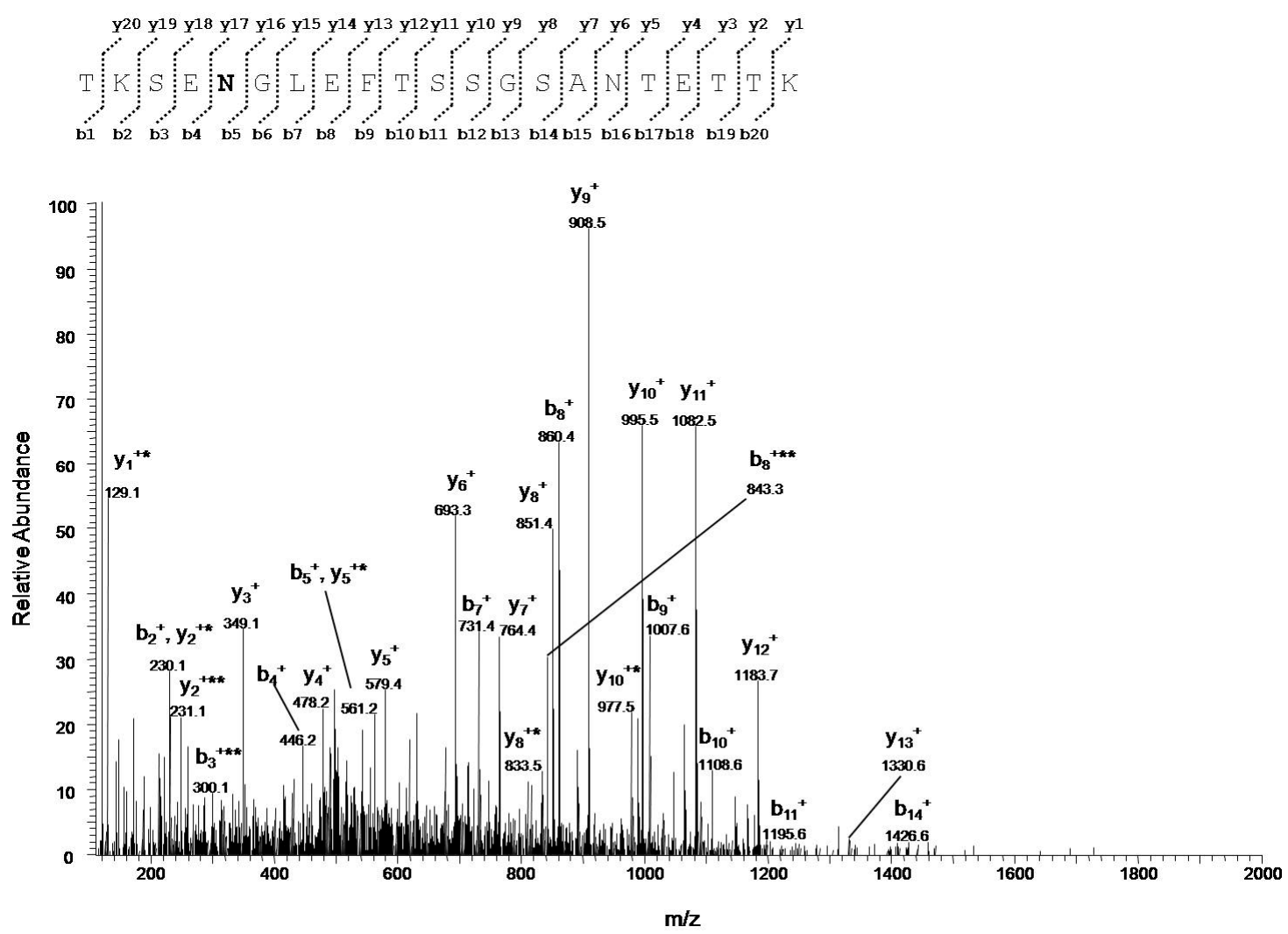

Figure 2. MS/MS spectrum of the triply charged molecular ion at $m / z 730.6730$ (calculated 730.6734) of the VDAC1 tryptic peptide from NSC34-SOD1G93Acellcontaining Asn residue 37 in the deamidated form. Fragment ions originated from the neutral loss of $\mathrm{H}_{2} \mathrm{O}$ are indicated by an asterisk. Fragment ions originated from the neutral loss of $\mathrm{NH}_{3}$ are indicated by two asterisk.

The occurrence of deamidation only in the NSC34-SOD1G93A cell line was also confirmed by the calculation of the percentage of deamidation in the VDAC1 for each cell line (Table 3). A remarkable difference in the deamidation between asparagine (mean 0.98) and glutamine residues (mean 0.02) was also found. 
Table 3. Asparagine (N) and glutamine (Q) deamidation in the VDAC1 from NSC34 cells HTP-preparations. Mean, standard deviation, (95\%) lower and upper confidence level and the number of scansions are reported.

\begin{tabular}{ccccccc}
\hline Cell Lines & Residue & Mean & Std & CI_Low & CI_Up & N. of Scansions \\
\hline \multirow{2}{*}{ NSC34 } & $\mathrm{N}$ & 0 & 0 & 0 & 0 & 51 \\
& $\mathrm{Q}$ & 0 & 0 & 0 & 0 & 30 \\
\hline \multirow{2}{*}{ NSC34-SOD1WT } & $\mathrm{N}$ & 0 & 0 & 0 & 0 & 61 \\
& $\mathrm{Q}$ & 0 & 0 & 0 & 0 & 41 \\
\hline \multirow{2}{*}{ NSC34-SOD1G93A } & $\mathrm{N}$ & 0.98 & 0.81 & 0.04 & 2.76 & 87 \\
& $\mathrm{Q}$ & 0.02 & 0.02 & 0.00 & 0.06 & 47 \\
\hline
\end{tabular}

(95\%) lower and upper confidence level were obtained from 1000 bootstrap.

\subsection{Semi-Quantitative Analysis of VDAC1 in NSC34 Cell Lines}

The LFQ intensities obtained from MaxQuant search allowed for an estimation of the percentage of each VDAC in every cell line (Table 4). All three cell lines presented VDAC1 as the most abundant isoform (one order of magnitude higher than the other isoforms). However, NSC34 and NSC34-SOD1WT cell lines showed a similar profile for all the isoforms, whereas the NSC34-SOD1G93A cells had a difference in the abundance of VDAC2 and VDAC3. VDAC2 levels were higher in NSC34-SOD1G93A cells compared to NSC34 and NSC34-SOD1WT cell lines. In contrast, VDAC3 levels were lower in NSC34-SOD1G93A cells compared to NSC34 and NSC34-SOD1WT cell lines. The high complexity of the peptide mixtures could affect the reproducibility of the analysis, explaining the high standard deviation in NSC34-SOD1WT cells. Hence, caution about these results is required, although they may represent an interesting hint for further investigations.

Table 4. Relative percentage of each VDAC isoform in the three cell lines.

\begin{tabular}{|c|c|c|c|c|c|c|c|c|c|}
\hline \multirow[b]{2}{*}{ Protein } & \multicolumn{3}{|c|}{ NSC34 } & \multicolumn{3}{|c|}{ NSC34-SOD1WT } & \multicolumn{3}{|c|}{ NSC34-SOD1G93A } \\
\hline & $\begin{array}{c}\text { LFQ } \\
\text { Intensity }\end{array}$ & $\mathrm{SD} \%$ & $\%$ & $\begin{array}{c}\text { LFQ } \\
\text { Intensity }\end{array}$ & SD \% & $\%$ & $\begin{array}{c}\text { LFQ } \\
\text { Intensity }\end{array}$ & SD \% & $\%$ \\
\hline VDAC1 & $1.10 \times 10^{9}$ & 1 & 66.71 & $1.19 \times 10^{9}$ & 27 & 65.67 & $1.10 \times 10^{9}$ & 7 & 64.08 \\
\hline VDAC2 & $2.40 \times 10^{8}$ & 4 & 14.55 & $2.46 \times 10^{8}$ & 20 & 13.59 & $3.51 \times 10^{8}$ & 11 & 20.43 \\
\hline VDAC3 & $3.09 \times 10^{8}$ & 15 & 18.74 & $3.75 \times 10^{8}$ & 16 & 20.74 & $2.66 \times 10^{8}$ & 13 & 15.50 \\
\hline
\end{tabular}

\subsection{Bioinformatic Analysis Reveals an Increased Instability for Mutant Structures}

To evaluate the stability of VDAC1 mutants, the mouse crystal structure from PDB [35] was modified with substitution of one or more asparagine or glutamine with aspartate or glutamate, as "virtual" deamidated amino acids. Root-mean-square deviation (RMSD) between the unmodified structure and those carrying such deamidations was analyzed. RMSD measures the distance between the atoms in the backbone and those of a reference structure in a protein structure alignment. All the generated mutant structures were superimposed to VDAC1 wt obtaining in all cases high RMSD values. In particular, for the single mutants, the average RMSD values were $5.16 \AA$ for N37D, $5.28 \AA$ for N106D, $5.17 \AA$ for N214D, $4.79 \AA$ for N239D and 5.20 $\AA$ for N207D. Similar values were obtained for multiple mutants (5.33 $\AA$ and $5.59 \AA$ for 5 Asn/Asp and 5 Asn/Asp-2 Glu/Gln, respectively).

Overall, these results indicate that mutations produced a substantial modification in VDAC1 structure, likely affecting its molecule stability. Then, Ramachandran plots (RPs) were generated to determine $\varphi$ and $\psi$ angles for each amino acid residue (Table 5). This information, indeed, is very helpful for structure predictions since it describes the specific orientation of each residue in space. For example, RP for VDAC1 WT indicates that majority of amino acid residues are arranged in 
a $\beta$-strand structure (about 78\%) while the rest is distributed between $\alpha$-helix (8.7\%) and outlier conformations $(12.3 \%)$.

As reported in Table 5, the presence of single mutations specifically affects the distribution of the secondary structures. However, most of the differences were observed for multiple mutants in which, in front of a slight decrease of $\beta$-strand structures, the percentage of $\alpha$-helix increased proportionally to outlier reduction. Structural modifications produced by amino acid substitutions were confirmed by molecular modelling analysis (Figures 3-5). In Figures 3 and 4, structural reconstructions of the crystal and mutated sequences are shown. The models visually confirm the results obtained by RMSD calculations and outlined in the secondary structure content determined by the RPs.

Table 5. Distribution of secondary structures as predicted by Ramachandran Plot analysis. The table reports the percentage of allowed, favored and total secondary structure consisting of outliers, $\beta$-strand or $\alpha$-helix, as obtained by RP analysis of VDAC1 WT and mutant structures.

\begin{tabular}{cccccccc}
\hline & Outliers & & $\beta$-Strand & & \multicolumn{3}{c}{$\alpha$-Helix } \\
\hline & Total & Allowed & Favored & Total & Allowed & Favored & Total \\
\hline VDAC1 WT & 12.4 & 11.3 & 67.6 & 78.9 & 6.3 & 2.4 & 8.7 \\
VDAC1 N37D & 10.6 & 13.5 & 63.2 & 76.7 & 7.8 & 4.9 & 12.7 \\
VDAC1 N106D & 8.8 & 12.8 & 65.4 & 78.2 & 7.0 & 6.0 & 13.0 \\
VDAC1 N207D & 9.1 & 13.6 & 64.6 & 78.2 & 7.4 & 5.3 & 12.7 \\
VDAC1N214D & 7.7 & 12.3 & 66.1 & 78.4 & 6.7 & 7.1 & 13.8 \\
VDAC1N239D & 8.1 & 12.3 & 66.4 & 78.7 & 7.1 & 6.1 & 13.2 \\
VDAC1 5 Asn/Asp & 7.3 & 16.6 & 60.7 & 77.3 & 8.4 & 7.0 & 15.4 \\
VDAC1 5 Asn/Asp + 2 Gln/Glu & 7.7 & 14.4 & 60.7 & 75.1 & 8.4 & 8.4 & 16.8 \\
\hline
\end{tabular}
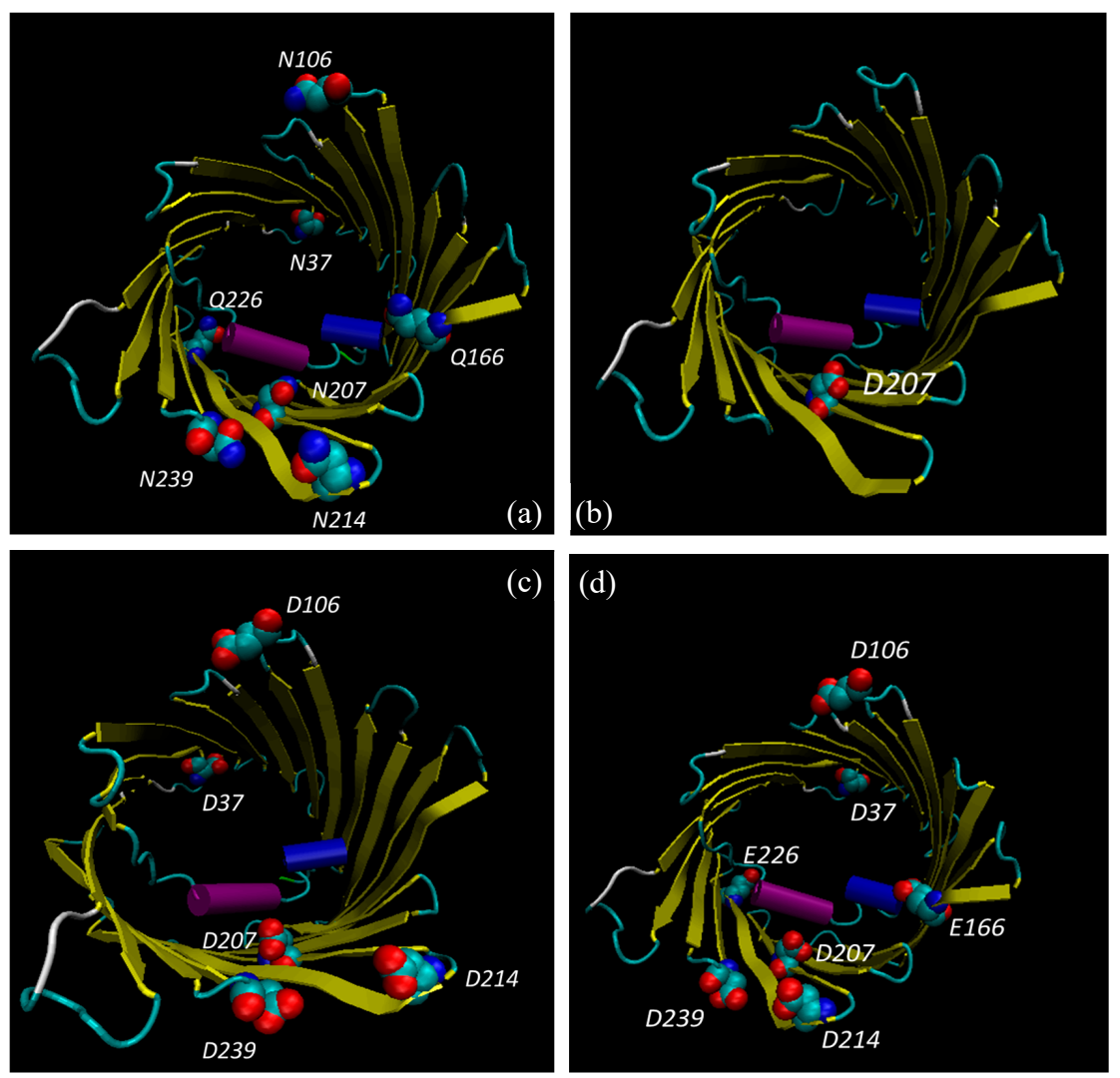

Figure 3. Top view of VDAC1 structures. Graphic representation of VDAC1 structures obtained by modelling WT (PDB: 3EMN) (a), mutant N207D (b), deamidated mutant 5 Asn/Asp (c) and deamidated mutant 5 Asn/Asp 2 Gln/Glu (d). N-terminal $\alpha$-helix is shown in purple, $\beta$-strands in yellow, unstructured loops/regions in white and light blue. The amino acid residues Asn, Gln and Asp are evidenced. Dark blue was used for nitrogen, red for oxygen and light blue for carbon atoms. 

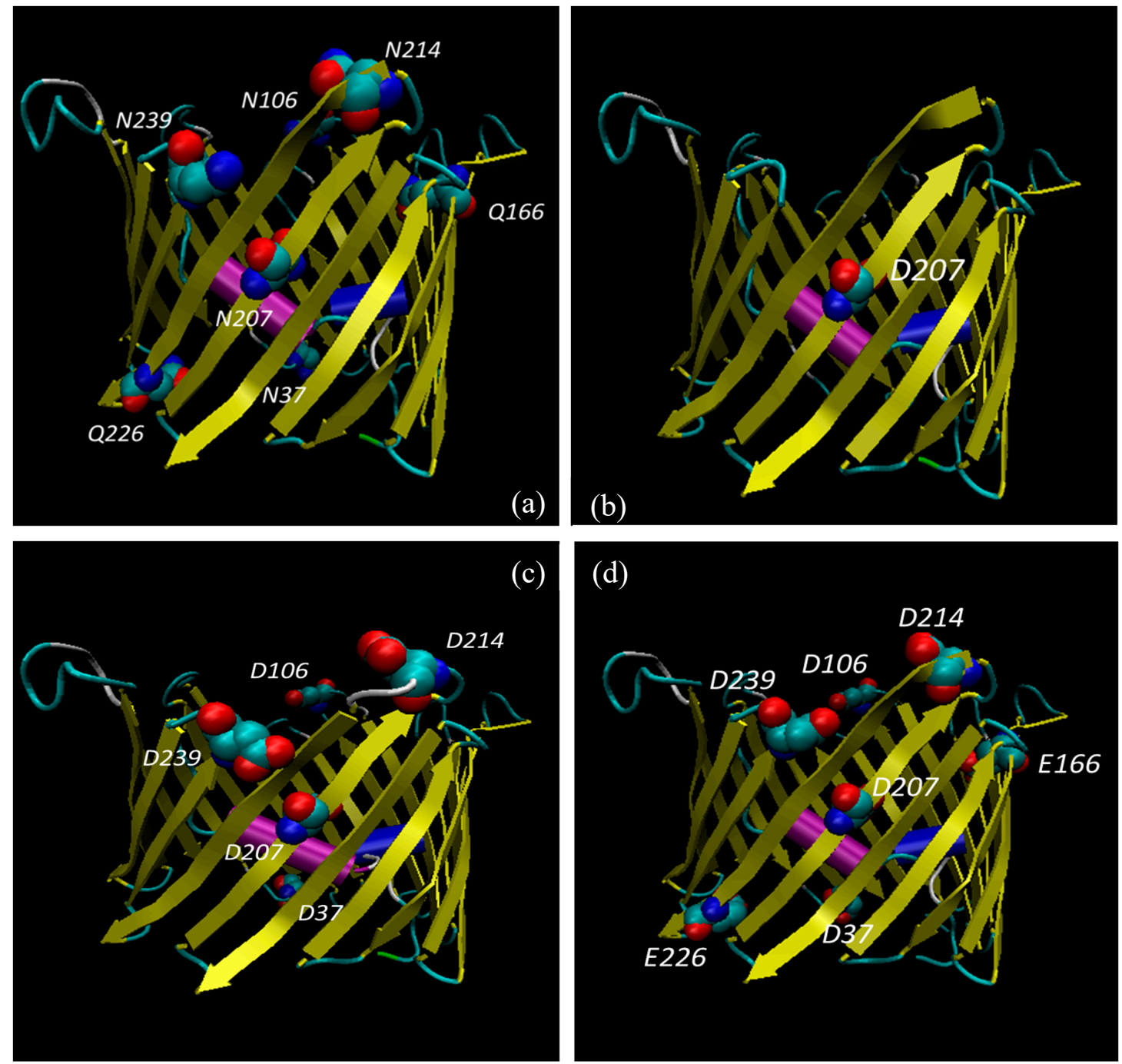

Figure 4. Lateral view of VDAC1 structures. Graphic representation of VDAC1 structures obtained by modelling of WT (PDB: 3EMN) (a), mutant N207D (b), deamidated mutant 5 Asn/Asp (c) and deamidated mutant $5 \mathrm{Asn} / \mathrm{Asp} 2 \mathrm{Gln} / \mathrm{Glu}$ (d). N-terminal $\alpha$-helix is shown in purple, $\beta$-strands in yellow, unstructured loops/regions in white and light blue. The amino acid residues Asn, Gln and Asp were evidenced. Dark blue was used for nitrogen, red for oxygen and light blue for carbon atoms.

The deamidation of the selected asparagine and glutamine causes a crushing of the barrel (see Figure $4 c$, for example) and a shift of the global secondary structure composition from $\beta$-strand to $\alpha$-helix. What is important is that even a single deamidation has a major structural effect (Figures 3 and 4 ).

It is interesting that the amino acids found deamidated in the cell expressing the mutated SOD1 are mostly located in loops or turns connecting the $\beta$-strands: they are, thus, in a water-exposed context where the effect of ROS can be faster. Only $\mathrm{Asn}^{37}$ and $\mathrm{Gln}^{226}$ protrude in the intermembrane space, while Asn ${ }^{106}, \mathrm{Asn}^{214}, \mathrm{Asn}^{239}$ and Gln ${ }^{166}$ protrude in the cytosol. The only exception is Asn ${ }^{207}$ which is located in the middle of a $\beta$-strand, even though it is exposed to the water interior of the pore, thus still accessible to ROS by diffusion. Interestingly, $\mathrm{Asn}^{207}$ is also the most frequently deamidated residue (see Table 6) and its modification results in a sensible change of the structure (Figures $3 b$ and $4 b$ ), indicating a crucial function for this residue. 

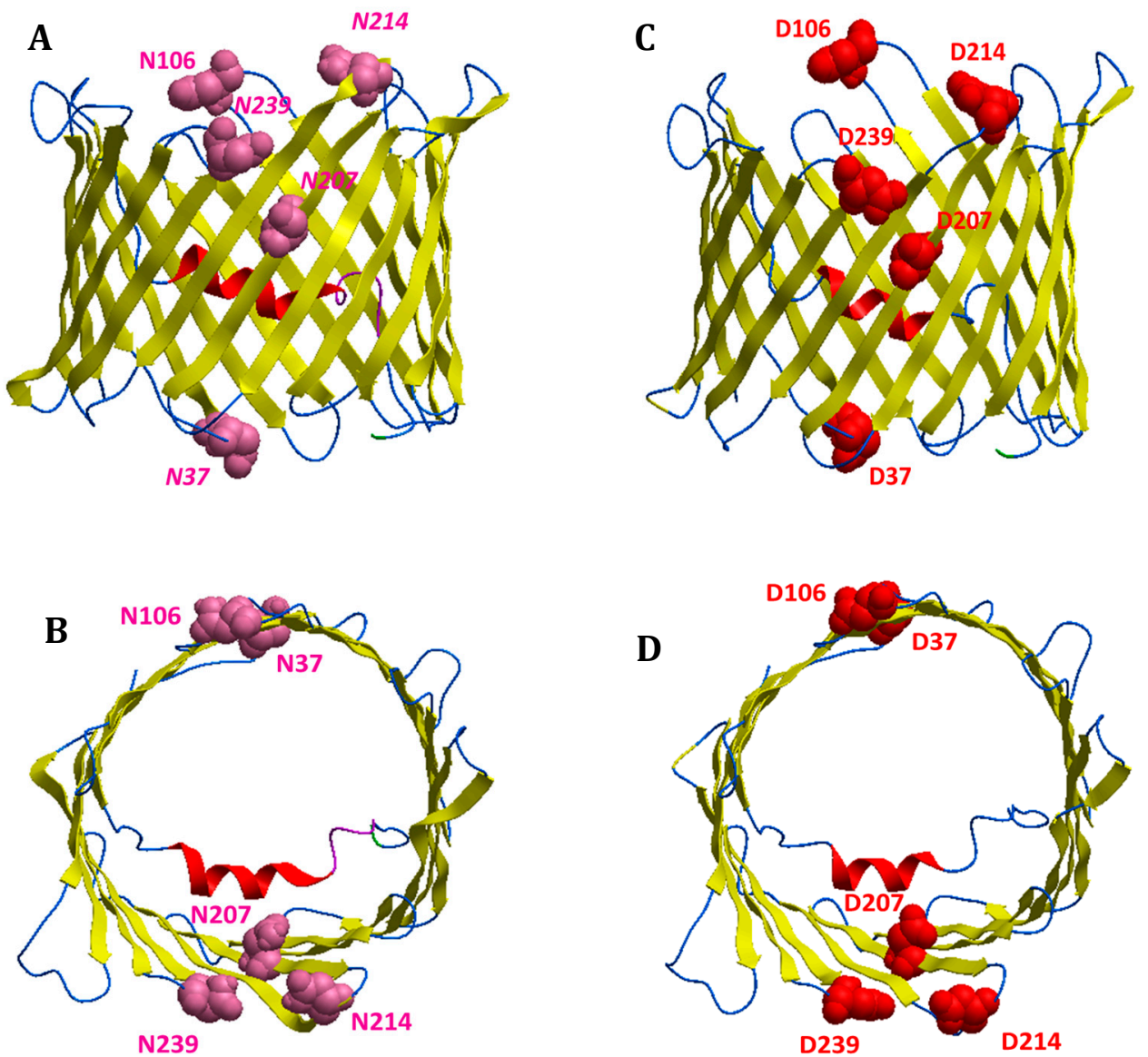

Figure 5. Polarity changes upon VDAC1 deamidation. Graphic representation of VDAC1 structures obtained by modelling in which polarity of specific amino acid residues has been highlighted. Lateral and top view of VDAC1 WT $(\mathbf{A}, \mathbf{C})$ and 5 Asn/Asp deamidated mutant (B,D). Pink color is used for amino acid residues having a neutral lateral chain, while red color is used for negatively charged residues.

Table 6. Modified residues found in VDAC1 from NSC34, NSC34-SOD1WT and NSC34-SOD1G93A cell lines. The ratio between modified and unmodified residues is shown in brackets; where the ratio is not indicated the residue is only present in a single form. The dashes indicate residues found exclusively in non-modified form. The asterisk indicates a fully carboxyamidomethylated form.

\begin{tabular}{|c|c|c|c|}
\hline & \multicolumn{3}{|c|}{ Modified Residues in VDAC1 } \\
\hline & NSC34 & NSC34-SOD1WT & NSC34-SOD1G93A \\
\hline ALA $^{2}$ & Acetylated & Acetylated & Acetylated \\
\hline $\mathrm{ASN}^{37}$ & - & - & Deamidated (0.01:1) \\
\hline SER 104 & Phosphorylated (0.01:1) & Phosphorylated (0.01:1) & Phosphorylated (0.01:1) \\
\hline ASN 106 & 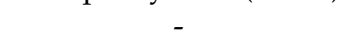 & 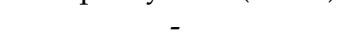 & Deamidated (0.01:1) \\
\hline CYS ${ }^{127}$ & Sulfonic acid & Sulfonic acid & Sulfonic acid (24:1) \\
\hline & Met sulfoxide (5:1) & Met sulfoxide (3:1) & Met sulfoxide (61:1) \\
\hline MET 100 & Met sulfone (0.1:1) & Met sulfone (0.1:1) & Met sulfone (4.7:1) \\
\hline GLN ${ }^{166}$ & - & - & Deamidated (0.002:1) \\
\hline ASN 207 & - & - & Deamidated (0.6) \\
\hline ASN 214 & - & - & Deamidated (0.04:1) \\
\hline GLN $^{226}$ & - & - & Deamidated (0.002:1) \\
\hline CYS ${ }^{232}$ & * & * & * \\
\hline $\mathrm{ASN}^{239}$ & - & - & Deamidated (0.03) \\
\hline
\end{tabular}




\section{Discussion}

The impairment of the bioenergetics metabolism strongly increases free radicals and oxidative stress, which, in turn, are involved in ALS onset and progression. Reactive species damage proteins by inducing various oxidative PTMs some of which are biological markers of misfolding disorders, including Parkinson's disease, Alzheimer's disease, and ALS [36-38]. In particular, carbonylation of spinal cord proteins has been proposed as a promoting factor of neuronal death in ALS [39,40]. Further reports showed the importance of other PTMs in ALS-related proteins. In particular, SOD1 mutants exhibit structural instability and propensity to exist in an unfolded state as well as presenting specific secondary post-translational changes [41]. Interestingly, by altering the normal set of PTMs [42,43] and/or inserting mutations which result in the same chemical structure as the PTM deamidation $(\mathrm{N} \rightarrow \mathrm{D} ; \mathrm{Q} \rightarrow \mathrm{E})$, the wild type SOD1 becomes unstable and misfolds, acquiring properties similar to those of fALS-related SOD1 mutants [44]. Therefore, certain PTMs are responsible for important chemical and biophysical characteristics of mutant SOD1 and may be involved in sporadic ALS. Equally relevant to understanding the role of mitochondrial dysfunction in SOD1 linked-ALS are the non-inheritable PTMs of VDAC1, an outer mitochondrial membrane (OMM) scaffold protein able to interact with ALS-linked SOD1 mutants but not with SOD1 wt.

Evidence of oxidative damage to proteins, lipids and DNA has been found both in animal ALS models expressing mutated human SOD1 and in post-mortem tissues of patients with sporadic or familial ALS [7]. In particular, deamidation events were found in erythrocytes of sALS patients [45] and in other tissues from patients with ALS-SOD1G93A [44]. Specific PTM, including N-D e Q-E deamidation, were also found in TDP-43 aggregates from brains of ALS patients [46]. There is no report in the literature where deamidation PTMs were looked for in animals.

In this study, by high-resolution mass spectrometry analysis, possible signs of oxidative damage in VDAC1 from an ALS cell model were investigated. Using known techniques [22], difficulties associated with the analysis of membrane proteins were overcome and potential dangers of undesirable oxidation were avoided. We have achieved excellent VDAC1 sequence coverage from mitochondria isolated from NSC34 cell lines; 273 out of 282 amino acids in the VDAC1 sequence were identified (Figure 1). The non-covered regions corresponded to a few single amino acids and a short stretch (G220-A224) found in the $\beta$-strand 15 . We accurately determined the oxidative states of the cysteine and methionine residues of NSC34 mouse VDAC1. VDAC1 contains a single inner methionine, Met ${ }^{155}$, and only two cysteines, Cys $^{127}$ and $\mathrm{Cys}^{232}$, located in $\beta$-strands 10, 8 and 16 respectively. According to VDAC1's three-dimensional structure $[35,47,48]$, Met $^{155}$ and Cys ${ }^{127}$ are embedded in the hydrophobic milieu of the OMM, whereas $\mathrm{Cys}^{232}$ turns toward the water-filled pore. Mass spectrometry analysis revealed an evolutionarily conserved redox modification pattern of VDAC1 cysteine residues: both in human and rat, $\mathrm{Cys}^{127}$ was exclusively found as trioxidized to sulfonic acid and $\mathrm{Cys}^{232}$ was fully reduced and carboxyamidomethylated [22,28]. Still, a functional role for these residues has never been demonstrated. Data available so far report that cysteines in VDAC1 do not influence the channel activity [49] and are not involved in protein oligomerization [50].

In our study, only in NSC34-SOD1G93A cells, we found that Met ${ }^{155}$ was oxidized to methionine sulfone and mostly over-oxidized to methionine sulfoxide also in much higher amounts than the one found for the same residue in the two non-ALS cell lines. Regarding the other residues, Cys ${ }^{232}$ was confirmed as completely reduced or involved in forming disulfide bridges in ALS and non-ALS cell lines [28]. Conversely, Cys ${ }^{127}$ from SOD1-ALS cells was over-oxidized to sulfonic acid, in a lower amount than in the two non-ALS cell lines.

Oxidative modifications in both $\mathrm{Met}^{155}$ and $\mathrm{Cys}^{127}$ could be explained by their localization in neighboring $\beta$-sheet where they face the lipid bilayer. Thus, we hypothesize that OMM lipids peroxidized by ALS pathogenesis [51] can modify susceptible residues oriented towards the membrane. A low amount of the Cys ${ }^{127}$ was also in carboxyamidomethylated form, therefore in a reduced form or involved in an intermolecular disulfide bridge (due to cysteines position in VDAC1). The finding of a putatively reduced aliquot of $\mathrm{Cys}^{127}$ could be a consequence of the destabilization of the VDAC1 
structure following all the modifications we identified. Indeed, we have also revealed only in NSC34-SOD1G93A cells, the deamidation of specific asparagine and glutamine residues. This is the first time that these changes were reported in VDAC1. Deamidation is a non-inheritable PTM that introduces negative charges by removing amino groups from asparagine and, with a much lower frequency and rate, glutamine [52,53]. This modification is strongly associated with the regulation of protein folding and turnover. While in vivo enzymatic deamidation of Gln is known and is involved in several physiological and pathological processes, Asn deamidation is a non-enzymatic reaction and its process rate depends on several factors, including the protein sequence and structure, as well as temperature, ionic strength, and $\mathrm{pH}$. In particular, the propensity to undergo deamidation is considerably increased if an Asn residue is in a protein sequence followed by small, flexible, or hydrophilic amino acids [54]. Several examples of human deamidated proteins are known, most of which are implicated in neurodegeneration [44,55-57].

As it causes critical alterations in peptide and protein structure, deamidation is suspected to contribute to the aging of proteins and protein folding disorders such as those observed in Alzheimer's disease [56-58]. It has also been demonstrated that specific deamidations of SOD1 wt determine aberrant conformations in the protein similar to those of the mutated forms associated with fALS $[43,59]$.

In this work, we found the surprising result of identifying deamidation of five asparagine $\left(\mathrm{Asn}^{37}, \mathrm{Asn}^{106}, \mathrm{Asn}^{207}, \mathrm{Asn}^{214}\right.$, and $\left.\mathrm{Asn}^{239}\right)$ and two glutamine $\left(\mathrm{Gln}^{166}\right.$ and $\left.\mathrm{Gln}^{226}\right)$ residues, exclusively in VDAC1 purified from NSC34-SOD1G93A cell line (Figure 2, Tables 2, 5 and 6). In particular, we found that the deamidation level of the $\mathrm{Asn}^{207}$ residue was much higher than other asparagine residues converted to aspartate, and especially that the two glutamines were modified to glutamate in a very small quantity (Tables 2 and 6). This may depend on the particular position of $\mathrm{Asn}^{207}$ in the VDAC1 sequence. In fact, this residue is located in the centre of the $\beta$-strand 14 and is preceded and followed by non-bulky amino acid residues, such as the nearby residues in the flanking $\beta$-strands (Figures 3 and 4). As a result of this, the amido group of $\mathrm{Asn}^{207}$ can be particularly sensitive to ROS at the inner mitochondrial membrane (IMM) which are strongly increased in ALS, as well as being affected by the aggressive action of peroxidized lipids in the OMM. The lower level of deamidation of the $\mathrm{Asn}^{37}$ residue could depend on its position in a loop, a domain that, although facing the oxidizing environment of the IMM, constitutes an unfolded region and therefore it is free to move and/or establish interactions with other molecules as well as to protect the $\mathrm{Asn}^{37}$ from the action of ROS (Figures 3 and 4). The other three asparagine residues (Asn ${ }^{106}, \mathrm{Asn}^{214}$ and $\mathrm{Asn}^{239}$ ) are also found in the loops (Figures 3 and 4), but unlike $\mathrm{Asn}^{37}$ these loops are exposed to the cytosol, a much less oxidizing environment than IMM.

We are sure that the different levels of oxidation and deamidation of VDAC1 identified in this study were not due to different protein expression in ALS motor neurons. In fact, an equal expression of VDAC1 was found in the three cell lines analysed, while VDAC2 levels were increased only in the ALS model NSC34 (Table 4). This result could be explained by considering the anti-apoptotic role of VDAC2 isoform, which could answer to degeneration signs characteristic of ALS. Deamidation introduces a negative charge in the protein sequence and, as a result, is often responsible for a serious change in its structure. RMSD analysis performed on the predicted structures for deamidated mouse VDAC1 showed that deamidation undoubtedly modifies the VDAC1 protein structure.

Structural predictions obtained by molecular modelling support data from RMSD analysis. Interestingly, conformational changes in deamidated VDAC mutants were found. In particular, it should be noted that the $\mathrm{Asn}^{207} / \mathrm{Asp}^{207}$ replacement alone causes structural modifications to the VDAC1 channel that becomes more and more marked as the number of deamidations increases (Figures 3 and 4). The distribution of the charges in the structures of the deamidated VDAC1 is also remarkably interesting: the replacement of the five asparagines and the two glutamines with the same number of aspartates and glutamates, respectively, increases the number of negative charges on the pore surfaces facing the cytosol and the intermembrane space (Figure 5). This different charge 
distribution must have an impact on the physiological interactivity of VDAC1 and consequently on the functionality of the protein itself and of the whole mitochondrion.

Moreover, in the predicted structures we have also observed that Met ${ }^{155}$ and Cys ${ }^{127}$ in deamidated VDAC1 maintain their original arrangement, although the sulphur of Met ${ }^{155}$ is further exposed to the lipid environment. In addition, we found that the atomic distance between $\mathrm{Cys}^{127}$ and the nearby residues was for Leu ${ }^{125}$ decreased from 10.2 A in VDAC1 WT to 8.6 A in deamidated VDAC1, shielding on one side the $\mathrm{Cys}^{127}$ in the sulfonic acid form (data not showed). These data may explain the small amount of $\mathrm{Cys}^{127}$ in reduced form found in ALS model cells.

RMSD data were confirmed by Ramachandran plot (RP) analysis for each single deamidated VDAC form identified in this study. Structural modifications were detected in the $\beta$-barrel regions of VDAC1 mutants together with an increased number of residues in the a-helix region, indicating a tendency for this domain to organise itself into a more stable structure. This effect, which causes destabilisation of the whole VDAC1 structure and pushes towards alpha helix formation, already occured with the N207D mutant or any other evaluated single mutant. Interestingly, RPs show that this trend increase with the rise of deamidation sites. It is reasonable to believe that the different levels of deamidation of the residues identified in VDAC1 may depend on the degree of disease that NSC34-SOD1G93A cells reflect. It is conceivable that the level of deamidation of VDAC1 will gradually increase with the worsening of the disease (Figure 6). D'Angelo S. et al. [45] reported the abnormal deamidation of protein asparagine residues in erythrocytes from sALS patients. In this perspective, the search for deamidated VDAC in blood or cerebrospinal fluid could represent an innovative diagnostic and/or prognostic biomarker of amyotrophic lateral sclerosis.

A

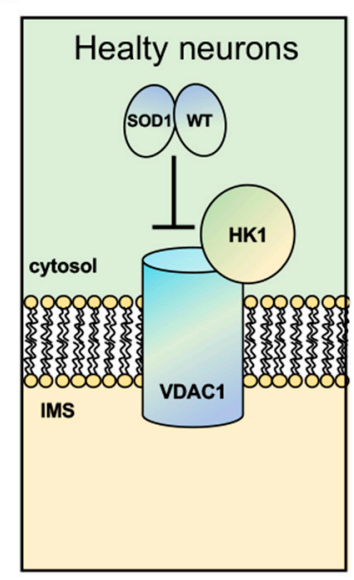

B

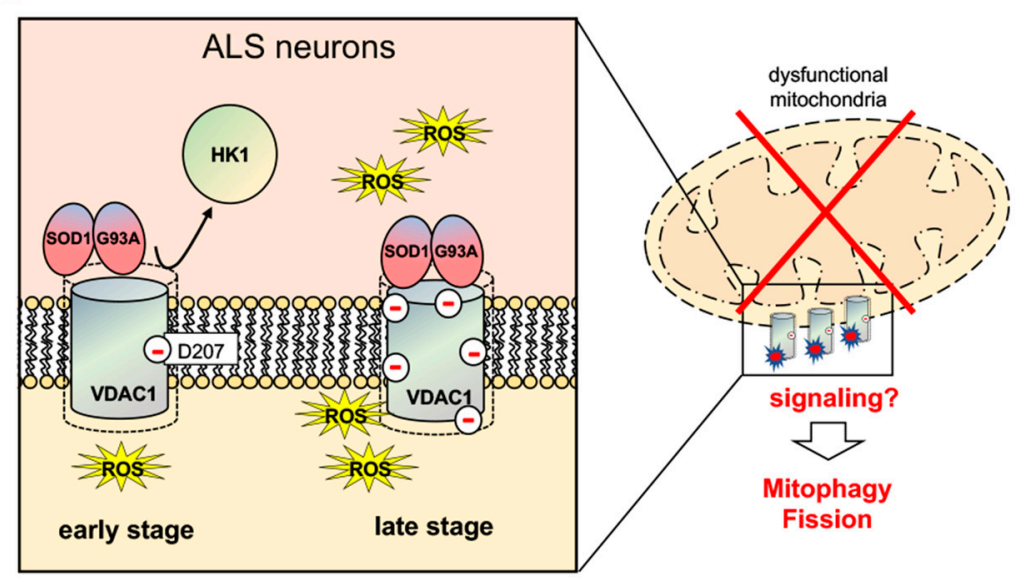

Figure 6. Deamidated VDAC1 in ALS motor neurons can promote mitochondrial dysfunction and ultimately lead to mitophagy. In physiological conditions (A), VDAC1 is the receptor of $\mathrm{HK} 1$ and of many other enzymes and metabolites (not shown), but not of SOD1WT. Conversely, in ALS (B), SOD1G93A is able to bind deamidated VDAC1 impairing thus the binding of HK1 and likely of others physiological interactors. We propose that deamidation of VDAC1 residues parallels oxidative stress levels, leading to the enhancement of SOD1 mutant binding to VDAC1. As a consequence, VDAC1 channel conductance and metabolic exchanges through VDAC1 are gradually affected, promoting a growing mitochondrial dysfunction. The oxidative damage that accumulates with disease progression produces therefore dysfunctional mitochondria tagged with deamidated VDAC1 that could be selected and forwarded to mitophagy or fission processes. In figure, red minus signs indicate deamidated VDAC1 amino acids.

\section{Conclusions}

In this work, we have established for the first time that in a motor neuron model of ALS, VDAC1 undergoes specific post-translational modifications, such as oxidations and deamidations. In addition, we have provided evidence of changes in the structure of deamidated VDAC1, a condition 
sufficient to alter the physiological pool of interactors. These data are important to understand how the VDAC1 protein interacts uniquely with the mutant SOD1 mutant but also allows us to better understand ALS pathogenesis. Furthermore, a new role as a potential marker for degenerated and unrepairable mitochondria in ALS emerges for VDAC1.

Supplementary Materials: The following are available online at http://www.mdpi.com/2076-3921/9/12/1218/s1, Figure S1: Map of the modified residues found in VDAC1 from the analyzed NSC34 cell lines. Figure S2: MS/MS and full scan mass spectra of the triply charged molecular ion at $\mathrm{m} / \mathrm{z} 817.3960$ (calculated 817.3951) of the VDAC1 tryptic peptide from NSC34 cell line containing the methionine residue 155 in the oxidized form of methionine sulfoxide. Figure S3: Full scan mass spectrum of the doubly charged molecular ion at $m / z 1233.5824$ (calculated 1233.5862) of the VDAC1 tryptic peptide from NSC34 cell line containing the methionine residue 155 in the oxidized form of methionine sulfone. Figure S4: MS/MS and full scan mass spectra of the doubly charged molecular ion at $m / z 1059.9929$ (calculated 1059.9919) of the VDAC1 tryptic peptide from NSC34 cell line containing cysteine residue 127 in the form of sulfonic acid. Figure S5: MS/MS and full scan mass spectra of the triply charged molecular ion at $\mathrm{m} / \mathrm{z} 817.3956$ (calculated 817.3951 ) of the VDAC1 tryptic peptide from NSC34-SOD1WT cell line containing the methionine residue 155 in the oxidized form of methionine sulfoxide. Figure S6: Full scan mass spectrum of the doubly charged molecular ion at $\mathrm{m} / \mathrm{z} 1233.5853$ (calculated 1233.5862) of the VDAC1 tryptic peptide from NSC34-SOD1WT cell line containing the methionine residue 155 in the oxidized form of methionine sulfone. Figure S7: MS/MS and full scan mass spectra of the doubly charged molecular ion at $\mathrm{m} / \mathrm{z} 1059.9924$ (calculated 1059.9919) of the VDAC1 tryptic peptide from NSC34-SOD1WT cell line containing the cysteine residue 127 in the form of sulfonic acid. Figure S8: MS/MS and full scan mass spectra of the triply charged molecular ion at $m / z$ 817.3946 (calculated 817.3951) of the VDAC1 tryptic peptide from NSC34-SOD1G93A cell line containing the methionine residue 155 in the oxidized form of methionine sulfoxide. Figure S9: Full scan mass spectrum of the triply charged molecular ion at $\mathrm{m} / \mathrm{z} 822.7261$ (calculated 822.7268) of the VDAC1 tryptic peptide from NSC34-SOD1G93A cell line containing the methionine residue 155 in the oxidized form of methionine sulfone. Figure S10: MS/MS and full scan mass spectra of the doubly charged molecular ion at $\mathrm{m} / \mathrm{z} 1059.9921$ (calculated 1059.9919) of the VDAC1 tryptic peptide from NSC34-SOD1G93A cell line containing the cysteine residue 127 in the form of sulfonic acid. Figure S11: MS/MS and full scan mass spectra of the doubly charged molecular ion at $\mathrm{m} / \mathrm{z} 804.8689$ (calculated 804.8692 ) of the VDAC1 tryptic peptide from NSC34 cell line containing the serine residue 104 in the phosphorylated form. Figure S12: MS/MS and full scan mass spectra of the doubly charged molecular ion at $m / z$ 804.8690 (calculated 804.8692) of the VDAC1 tryptic peptide from NSC34-SOD1WT cell line containing the serine residue 104 in the phosphorylated form. Figure S13: MS/MS and full scan mass spectra of the triply charged molecular ion at $m / z 536.9153$ (calculated 536.9154) of the VDAC1 tryptic peptide from NSC34-SOD1G93A cell line containing the serine residue 104 in the phosphorylated form. Figure S14: MS/MS and full scan mass spectra of the doubly charged molecular ion at $m / z 587.3116$ (calculated 587.3111) of the N-terminal acetylated tryptic peptide of VDAC1 from NSC34 cell line. Figure S15: MS/MS and full scan mass spectra of the doubly charged molecular ion at $m / z$ 587.3114 (calculated 587.3111) of the N-terminal acetylated tryptic peptide of VDAC1 from NSC34-SOD1WT cell line. Figure S16: MS/MS and full scan mass spectra of the doubly charged molecular ion at $m / z 587.3113$ (calculated 587.3111) of the N-terminal acetylated tryptic peptide of VDAC1 from NSC34-SOD1G93A cell line. Figure S17: MS/MS spectrum of the triply charged molecular ion at $\mathrm{m} / \mathrm{z} 654.2921$ (calculated 654.2925) of the VDAC1 tryptic peptide from NSC34-SOD1G93A cell line containing the asparagine residue 37 in the deamidated form. Figure S18: MS/MS spectrum of the triply charged molecular ion at $m / z 510.5876$ (calculated 510.5880) of the VDAC1 tryptic peptide from NSC34-SOD1G93A cell line containing the asparagine residue 106 in the deamidated form. Figure S19: MS/MS spectrum of the triply charged molecular ion at $m / z 649.6692$ (calculated 649.6696) of the VDAC1 tryptic peptide from NSC34-SOD1G93A cell line containing the asparagine residue 207 in the deamidated form. Figure S20: MS/MS spectrum of the doubly charged molecular ion at $m / z$ 909.9527 (calculated 909.9530) of the VDAC1 tryptic peptide from NSC34-SOD1G93A cell line containing the asparagine residue 214 in the deamidated form. Figure S21: MS/MS spectrum of the triply charged molecular ion at $\mathrm{m} / z$ 702.0598 (calculated 702.0602) of the VDAC1 tryptic peptide from NSC34-SOD1G93A cell line containing the asparagine residue 239 in the deamidated form. Figure S22: MS/MS spectrum of the doubly charged molecular ion at $\mathrm{m} / z 607.8062$ (calculated 607.8065) of the VDAC1 tryptic peptide from NSC34-SOD1G93A cell line containing the glutamine residue 166 in the deamidated form. Figure S23: MS/MS spectrum of the doubly charged molecular ion at $m / z 701.3032$ (calculated 701.3035) of the VDAC1 tryptic peptide from Mouse Motor Neuron-like NSC34-SOD1G93A cell line containing $\mathrm{Cys}^{232}$ residue in the carboxyamidomethylated form and the glutamine residue 226 in the deamidated form. Table S1: Tryptic peptides found in the analysis of VDAC1 from NSC34 cell line after DTT reduction and carboxyamidomethylation. Table S2: Chymotryptic peptides found in the analysis of VDAC1 from NSC34 cell line after DTT reduction and carboxyamidomethylation. Table S3: Retention time, experimentally measured and calculated monoisotopic $\mathrm{m} / \mathrm{z}$ of the molecular ions, position in the sequence and peptide sequence of sulfur containing tryptic fragments found in the analysis of VDAC1 from NSC34 cell line digest reduced with DTT, carboxyamidomethylated and digested in-solution. Table S4: Retention time, experimentally measured and calculated monoisotopic $m / z$ of the molecular ion of the Chymotryptic peptide $\mathrm{K}^{119}$ REHINLGCDVDF ${ }^{131}$ found in VDAC1 from NSC34 cell line digest reduced with DTT, carboxyamidomethylated and digested in-solution. Table S5: Ratio of the absolute intensities of the molecular ions of the sulfur and not sulfur containing tryptic peptide $G^{140}$ ALVLGYEGWLAGYQMNFETSK ${ }^{161}$ found in the analysis of VDAC1 from NSC34 cell line HTP-preparation reduced with DTT, carboxyamidomethylated and digested in-solution. Table S6: Tryptic peptides found in 
the analysis of VDAC1 from NSC34-SOD1WT cell line after DTT reduction and carboxyamidomethylation. Table S7: Chymotryptic peptides found in the analysis of VDAC1 from NSC34-SOD1WT cell line after DTT reduction and carboxyamidomethylation. Table S8: Retention time, experimentally measured and calculated monoisotopic $\mathrm{m} / \mathrm{z}$ of the molecular ions, position in the sequence and peptide sequence of sulfur containing tryptic fragments found in the analysis of VDAC1 from NSC34-SOD1WT cell line digest reduced with DTT, carboxyamidomethylated and digested in-solution. Table S9: Retention time, experimentally measured and calculated monoisotopic $m / z$ of the molecular ion of thechymotrypticpeptide $K^{119}$ REHINLGCDVDF ${ }^{131}$ found in the analysis of VDAC1 from NSC34-SOD1WT cell line digestreduced with DTT, carboxyamidomethylated and digested in-solution. Table S10: Ratio of the absolute intensities of the molecular ions of the sulfur and not sulfur containing tryptic peptide $\mathrm{G}^{140}$ ALVLGYEGWLAGYQMNFETSK ${ }^{161}$ found in the analysis of VDAC1 from NSC34-SOD1WT cell line digest reduced with DTT, carboxyamidomethylated and digested in-solution. Table S11: Tryptic peptides found in the analysis ofVDAC1 from NSC34-SOD1G93A cell line after DTT reduction and carboxyamidomethylation. Table S12: Chymotryptic peptides found in the analysis of VDAC1 from NSC34-SOD1G93A cell line after DTT reduction and carboxyamidomethylation. Table S13: Retention time, experimentally measured and calculated monoisotopic $\mathrm{m} / \mathrm{z}$ of the molecular ions, position in the sequence and peptide sequence of sulfur containing tryptic fragments found in VDAC1 from NSC34-SOD1G93A cell line digest reduced with DTT, carboxyamidomethylated and digested in-solution. Table S14: Retention time, experimentally measured and calculated monoisotopic $m / z$ of the molecular ion of the phosphorylated tryptic peptide $\mathrm{L}^{97}$ TFDSSFSPNTGKK $^{110}$ containing the Ser ${ }^{104}$ phosphorylated found in VDAC1 from NSC34 cell line digest reduced with DTT, carboxyamidomethylated and digested in-solution. Table S15: Retention time, experimentally measured and calculated monoisotopic $\mathrm{m} / \mathrm{z}$ of the molecular ion of the phosphorylated tryptic peptide $\mathrm{L}^{97}$ TFDSSFSPNTGKK ${ }^{110}$ containing the Ser ${ }^{104}$ phosphorylated found in VDAC1 from NSC34-SOD1WT cell line digest reduced with DTT, carboxyamidomethylated and digested in-solution. Table S16: Retention time, experimentally measured and calculated monoisotopic $\mathrm{m} / z$ of the molecular ion of the phosphorylated tryptic peptide ${ }^{97}{ }^{97}$ DSSFSPNTGKK ${ }^{110}$ containing the Ser ${ }^{104}$ phosphorylated found in VDAC1 from NSC34-SOD1G93A cell line digest reduced with DTT, carboxyamidomethylated and digested in-solution. Table S17: Ratio of the absolute intensities of the molecular ions of the phosphorylated and not phosphorylated tryptic peptide $\mathrm{L}^{97}$ TFDSSFSPNTGKK ${ }^{110}$ containing the Ser ${ }^{104}$ phosphorylated found in the analysis of VDAC1 from NSC34 cell line digest reduced with DTT, carboxyamidomethylated and digested in-solution. Table S18: Ratio of the absolute intensities of the molecular ions of the phosphorylated and not phosphorylated tryptic peptide $\mathrm{L}^{97}$ TFDSSFSPNTGKK ${ }^{110}$ containing the Ser ${ }^{104}$ phosphorylated found in the analysis of VDAC1 from NSC34-SOD1WT cell line digest reduced with DTT, carboxyamidomethylated and digested in-solution. Table S19: Ratio of the absolute intensities of the molecular ions of the phosphorylated and not phosphorylated tryptic peptide ${ }^{97}$ TFDSSFSPNTGKK ${ }^{110}$ containing the Ser ${ }^{104}$ phosphorylated found in the analysis of VDAC1 from NSC34-SOD1G93A cell line digest reduced with DTT, carboxyamidomethylated and digested in-solution. Table S20: Retention time, experimentally measured and calculated monoisotopic $\mathrm{m} / \mathrm{z}$ of the molecular ions, position in the sequence and peptide sequence of tryptic fragments containing asparagine and glutamine residues in deamidated form found in VDAC1 from NSC34-SOD1G93A cell line digest reduced with DTT, carboxyamidomethylated and digested in-solution.

Author Contributions: Conceptualization, A.M.; methodology, M.G.G.P. and R.S.; software, S.A.M.C., V.C., M.G.G.P. and A.C.; validation, M.G.G.P., A.C. and S.R.; investigation, M.G.G.P., S.R. and B.F.; writing-original draft preparation, M.G.G.P., S.R., R.S. and A.M.; writing-review and editing, R.S. and A.M.; supervision, S.F., R.S. and A.M. All authors have read and agreed to the published version of the manuscript.

Funding: This research was funded by Italian Ministry of University and Research-Proof of Concept 2018, grant number PEPSLA POC 01_00054 to A.M. and Università di Catania—linea PIACERI, grant number ARVEST.

Acknowledgments: The authors are grateful to Francesca Re (University of Milano-Bicocca), Salvatore Oddo (University of Messina), Vito De Pinto (University of Catania) and Andrea Magrì (University of Catania) for their valuable support, and to Maria Teresa Carrì (Rome, University of Tor Vergata) for providing all NSC34 cells used in the work. Authors also acknowledge Fondi di Ateneo 2020-2022, Università di Catania, linea Open Access. The mass spectrometry proteomics data have been deposited to the ProteomeXchange Consortium (http://proteomecentral.proteomexchange.org) via the PRIDE [60] partner repository with the dataset identifier <PXD022598>

Conflicts of Interest: The authors declare no conflict of interest.

\section{References}

1. Pasinelli, P.; Brown, R.H. Molecular biology of amyotrophic lateral sclerosis: Insights from genetics. Nat. Rev. Neurosci. 2006, 7, 710-723. [CrossRef] [PubMed]

2. Brown, R.H.; Al-Chalabi, A. Amyotrophic Lateral Sclerosis. N. Engl. J. Med. 2017, 377, 162-172. [CrossRef] [PubMed]

3. Barber, S.C.; Mead, R.J.; Shaw, P.L. Oxidative stress in ALS: A mechanism of neurodegeneration and a therapeutic target. Biochim. Biophys. Acta 2006, 1762, 1051-1067. [CrossRef] [PubMed] 
4. Massaad, C.A.; Klann, E. Reactive Oxygen Species in the Regulation of Synaptic Plasticity and Memory. Antioxid. Redox Signal. 2011, 14, 2013-2054. [CrossRef]

5. Marden, J.J.; Harraz, M.M.; Williams, A.J.; Nelson, K.; Luo, M.; Paulson, H.; Engelhardt, J.F. Redox modifier genes in amyotrophic lateral sclerosis in mice. J. Clin. Investig. 2007, 117, 2913-2919. [CrossRef]

6. Zuo, L.; Zhou, T.; Pannel, B.K.; Ziegler, A.C.; Best, T.M. Biological and physiological role of reactive oxygen species-the good, the bad and the ugly. Acta Physiol. 2015, 214, 329-348. [CrossRef]

7. Kaur, S.J.; McKeown, S.R.; Rashid, S. Mutant Sod1 mediated pathogenesis of amyotrophic lateral sclerosis. Gene 2016, 577, 109-118. [CrossRef]

8. Vande Velde, C.; Miller, T.M.; Cashman, N.R.; Cleveland, D.W. Selective association of misfolded ALS-linked mutant SOD1 with the cytoplasmic face of mitochondria. Proc. Natl. Acad. Sci. USA 2008, 105, 4022-4027. [CrossRef]

9. Ferri, A.; Cozzolino, M.; Crosio, C.; Nencini, M.; Casciati, A.; Gralla, E.B.; Rotilio, G.; Valentine, J.S.; Carrì, M.T. Familial ALS-superoxide dismutases associate with mitochondria and shift their redox potentials. Proc. Natl. Acad. Sci. USA 2006, 103, 13860-13865. [CrossRef] [PubMed]

10. Magrì, A.; Belfiore, R.; Reina, S.; Tomasello, M.F.; Di Rosa, M.C.; Guarino, F.; Leggio, L.; De Pinto, V.; Messina, A. Hexokinase I N-terminal based peptide prevents the VDAC1-SOD1 G93A interaction and re-establishes ALS cell viability. Sci. Rep. 2016, 6, 34802. [CrossRef] [PubMed]

11. Israelson, A.; Arbel, N.; Da Cruz, S.; Ilieva, H.; Yamanaka, K.; Shoshan-Barmatz, V.; Cleveland, D.W. Misfolded Mutant SOD1 Directly Inhibits VDAC1 Conductance in a Mouse Model of Inherited ALS. Neuron 2010, 67, 575-587. [CrossRef]

12. Magrì, A.; Di Rosa, M.C.; Orlandi, I.; Guarino, F.; Reina, S.; Guarnaccia, M.; Morello, G.; Spampinato, A.; Cavallaro, S.; Messina, A.; et al. Deletion of Voltage-Dependent Anion Channel 1 knocks mitochondria down triggering metabolic rewiring in yeast. Cell. Mol. Life Sci. 2020, 77, 3195-3213. [CrossRef]

13. Leggio, L.; Guarino, F.; Accardi-Gheit, R.; Reina, S.; Specchia, V.; Damiano, F.; Tomasello, M.F.; Tommasino, M.; Messina, A. Mechanism of translation control of the alternative Drosophila melanogaster Voltage Dependent Anion-selective Channel 1 mRNAs. Sci. Rep. 2018, 8, 5347. [CrossRef]

14. Guarino, F.; Zinghirino, F.; Mela, L.; Pappalardo, X.G.; Ichas, F.; De Pinto, V.; Messina, A. NRF-1 and HIF-1 $\alpha$ contribute to modulation of human VDAC1 gene promoter during starvation and hypoxia in HeLa cells. Biochim. Biophys. Acta Bioenerg. 2020, 1861, 148289. [CrossRef] [PubMed]

15. Keinan, N.; Tyomikin, D.; Shoshan-Barmatz, V. Oligomerization of the Mitochondrial Protein Voltage-Dependent Anion Channel Is Coupled to the Induction of Apoptosis. Mol. Cell. Biol. 2010, 30, 5698-5709. [CrossRef]

16. Reina, S.; De Pinto, V. Anti-cancer compounds targeted to VDAC: Potential and perspectives. Curr. Med. Chem. 2017, 24, 4447-4469. [CrossRef]

17. Magrì, A.; Reina, S.; De Pinto, V. VDAC1 as pharmacological target in cancer and neurodegeneration: Focus on its role in apoptosis. Front. Chem. 2018, 6, 108. [CrossRef]

18. Zilocchi, M.; Moutaoufik, M.T.; Jessulat, M.; Phanse, S.; Aly, K.A.; Babu, M. Misconnecting the dots: Altered mitochondrial protein-protein interactions and their role in neurodegenerative disorders. Expert Rev. Proteom. 2020, 17, 119-136. [CrossRef]

19. Martel, C.; Wang, Z.; Brenner, C. VDAC phosphorylation, a lipid sensor influencing the cell fate. Mitochondrion 2014, 19, 69-77. [CrossRef]

20. Yu, H.; Diao, H.; Wang, C.; Lin, Y.; Yu, F.; Lu, H.; Xu, W.; Li, Z.; Shi, H.; Zhao, S.; et al. Acetylproteomic analysis reveals functional implications of lysine acetylation in human spermatozoa (sperm). Mol. Cell. Proteom. 2015, 14, 1009-1023. [CrossRef]

21. Yang, M.; Camara, A.K.; Wakim, B.T.; Zhou, Y.; Gadicherla, A.K.; Kwok, W.M.; Stowe, D.F. Tyrosine nitration of voltage-dependent anion channels in cardiacischemia-reperfusion: Reduction by peroxynitrite scavenging. Biochim. Biophys. Acta 2012, 1817, 2049-2059. [CrossRef]

22. Saletti, R.; Reina, S.; Pittalà, M.G.G.; Magrì, A.; Cunsolo, V.; Foti, S.; De Pinto, V. Post-translational modifications of VDAC1 and VDAC2 cysteines from rat liver mitochondria. Biochim. Biophys. Acta Bioenerg. 2018, 1859, 806-816. [CrossRef]

23. Reina, S.; Pittalà, M.G.G.; Guarino, F.; Messina, A.; De Pinto, V.; Foti, S.; Saletti, R. Cysteine Oxidations in Mitochondrial Membrane Proteins: The Case of VDAC Isoforms in Mammals. Front. Cell. Dev. Biol. 2020, 8, 397. [CrossRef] 
24. Reina, S.; Checchetto, V.; Saletti, R.; Gupta, A.; Chaturvedi, D.; Guardiani, C.; Guarino, F.; Scorciapino, M.A.; Magrì, A.; Foti, S.; et al. VDAC3 as a sensor of oxidative state of the intermembrane space of mitochondria: The putative role of cysteine residue modifications. Oncotarget 2016, 7, 2249-2268. [CrossRef]

25. Sarraf, S.A.; Raman, M.; Guarani-Pereira, V.; Sowa, M.E.; Huttlin, E.L.; Gygi, S.P.; Harper, J.W. Landscape of the PARKIN-dependent ubiquitylome in response to mitochondrial depolarization. Nature 2013, 496, 372-376. [CrossRef]

26. Herst, P.M.; Rowe, M.R.; Carson, G.M.; Berridge, M.V. Functional Mitochondria in Health and Disease. Front. Endocrinol. 2017, 8, 296.

27. Hoogerheide, D.P.; Gurnev, P.A.; Rostovtseva, T.K.; Bezrukov, S.M. Effect of a post-translational modification mimic on protein translocation through a nanopore. Nanoscale 2020, 12, 11070-11078. [CrossRef]

28. Pittalà, M.G.G.; Saletti, R.; Reina, S.; Cunsolo, V.; De Pinto, V.; Foti, S. A High Resolution Mass Spectrometry Study Reveals the Potential of Disulfide Formation in Human Mitochondrial Voltage-Dependent Anion Selective Channel Isoforms (hVDACs). Int. J. Mol. Sci. 2020, 21, 1468. [CrossRef]

29. De Pinto, V.; Benz, R.; Caggese, C.; Palmieri, F. Characterization of the mitochondrial porin from Drosophila melanogaster. Biochim. Biophys. Acta 1989, 905, 499-502. [CrossRef]

30. Mackie, M.; Rüther, P.; Samodova, D.; Di Gianvincenzo, F.; Granzotto, C.; Lyon, D.; Peggie, D.A.; Howard, H.; Harrison, L.; Jensen, L.J.; et al. Palaeoproteomic Profiling of Conservation Layers on a 14th Century Italian Wall Painting. Angew. Chem. Int. Ed. 2018, 57, 7369-7374. [CrossRef]

31. Cox, J.; Hein, M.Y.; Luber, C.A.; Paron, I.; Nagaraj, N.; Mann, M. Accurate Proteome-wide Label-free Quantification by Delayed Normalization and Maximal Peptide Ratio Extraction, Termed MaxLFQ. Mol. Cell. Proteom. 2014, 13, 2513-2526. [CrossRef]

32. Guan, Z.Q.; Yates, N.A.; Bakhtiar, R. Detection and characterization of methionine oxidation in peptides by collision-induced dissociation and electron capture dissociation. J. Am. Soc. Mass Spectrom. 2003, 14, 605-613. [CrossRef]

33. Galliano, F.; Saletti, R.; Cunsolo, V.; Foti, S.; Marletta, D.; Bordonaro, S.; D’Urso, G. Identification and characterization of a new $\beta$-casein variant in goat milk by high-performance liquid chromatography with electrospray ionization mass spectrometry and matrix-assisted laser desorption/ionization mass spectrometry. Rapid Commun. Mass Spectrom. 2004, 18, 1972-1982. [CrossRef]

34. Cunsolo, V.; Muccilli, V.; Saletti, R.; Foti, S. Applications of mass spectrometry techniques in the investigation of milk proteome. Eur. J. Mass Spectrom. 2011, 17, 305-320. [CrossRef]

35. Ujwal, R.; Cascio, D.; Colletierc, J.P.; Fahama, S.; Zhanga, J.; Torod, L.; Ping, P.; Abramson, J. The crystal structure of mouse VDAC1 at 2.3 A resolution reveals mechanistic insights into metabolite gating. Proc. Natl. Acad. Sci. USA 2008, 105, 17742-17747. [CrossRef]

36. Didonna, A.; Benetti, F. Post-translational modifications in neurodegeneration. AIMS Biophys. 2016, 3, $27-49$. [CrossRef]

37. Michalska, P.; When, R.L. It Comes to an End: Oxidative Stress Crosstalk with Protein Aggregation and Neuro inflammation Induce Neurodegeneration. Antioxidants 2020, 9, 740. [CrossRef]

38. Shadel, G.S.; Horvath, T.L. Mitochondrial ROS Signalingin Organismal Homeostasis. Cell 2015, 163, 560-569. [CrossRef]

39. Andrus, P.K.; Fleck, T.J.; Gurney, M.E.; Hall, E.D. Protein oxidative damage in a transgenic mouse model of familial amyotrophic lateral sclerosis. J. Neurochem. 1998, 71, 2041-2048. [CrossRef]

40. Niebroj-Dobosz, I.; Dziewulska, D.; Kwiecinski, H. Oxidative damage to proteins in the spinal cord in amyotrophic lateral sclerosis (ALS). Folia Neuropathol. 2004, 42, 151-156.

41. Wright, G.S.A.; Antonyuk, S.V.; Hasnain, S.S. The biophysics of superoxide dismutase-1 and amyotrophic lateral sclerosis. Q. Rev. Biophys. 2019, 52, e12. [CrossRef]

42. Martins, D.; English, A.M. SOD1 oxidation and formation of soluble aggregates in yeast: Relevance to sporadic ALS development. Redox Biol. 2014, 26, 632-639. [CrossRef]

43. Banks, C.J.; Andersen, J.L. Mechanisms of SOD1 regulation by post-translational modifications. Redox Biol. 2019, 26, 101270. [CrossRef]

44. Schmitt, N.D.; Agar, J.N. Parsing Disease-relevant Protein Modifications from Epiphenomena: Perspective on the Structural Basis of SOD1-Mediated ALS. J. Mass Spectrom. 2017, 52, 480-491. [CrossRef] 
45. D'Angelo, S.; Trojsi, F.; Salvatore, A.; Daniele, L.; Raimo, M.; Galletti, P.; Monsurrò, M.R. Accumulation of altered aspartyl residues in erythrocyte membrane proteins from patients with sporadic amyotrophic lateral sclerosis. Neurochem. Int. 2013, 63, 626-634. [CrossRef]

46. Kametani, F.; Obi, T.; Shishido, T.; Akatsu, H.; Murayama, S.; Saito, Y.; Yoshida, M.; Hasegawa, M. Mass spectrometric analysis of accumulated TDP-43 in amyotrophic lateral sclerosis brains. Sci Rep. 2016, 6, 23281. [CrossRef]

47. Bayrhuber, M.; Meins, T.; Habeck, M.; Becker, S.; Giller, K.; Villinger, S.; Vonrhein, C.; Griesinger, C.; Zweckstetter, M.; Zeth, K. Structure of the human voltage-dependent anion channel. Proc. Natl. Acad. Sci. USA 2008, 105, 15370-15375. [CrossRef]

48. Hiller, S.; Garces, R.G.; Malia, T.J.; Orekhov, V.Y.; Colombini, M.; Wagner, G. Solution structure of the integral human membrane protein VDAC-1 in detergent micelles. Science 2008, 321, 1206-1210. [CrossRef]

49. De Pinto, V.; Al Jamal, J.A.; Benz, R.; Genchi, G.; Palmieri, F. Characterization of SH groups in porin of bovine heart mitochondria. Porin cysteines are localized in the channel walls. J. Biochem. 1991, 202, 903-911. [CrossRef]

50. Aram, L.; Geula, S.; Arbel, N.; Shoshan-Barmatz, V. VDAC1 cysteine residues: Topology and function in channel activity and apoptosis. Biochem. J. 2010, 427, 445-454. [CrossRef]

51. Ravera, S.; Bonifacino, T.; Bartolucci, M.; Milanese, M.; Gallia, E.; Cortese, K.; Pandolfi, I.; Bonanno, G. Characterization of the Mitochondrial Aerobic Metabolismin the Pre- and Perisynaptic Districts of the SOD1G93A Mouse Model of Amyotrophic Lateral Sclerosis. Mol. Neurobiol. 2018, 55, 9220-9233. [CrossRef] [PubMed]

52. Wright, H.T. Nonenzymatic deamidation of asparaginyl and glutaminyl residues in proteins. Crit. Rev. Biochem. Mol. Biol. 1991, 26, 1-52. [CrossRef] [PubMed]

53. Robinson, N.E.; Robinson, Z.W.; Robinson, B.R.; Robinson, A.L.; Robinson, J.A.; Robinson, M.L.; Robinson, A.B. Structure-dependent nonenzymatic deamidation of glutaminyl and asparaginyl pentapeptides. J. Pept. Res. 2004, 63, 426-436. [CrossRef]

54. Mikkat, S.; Kischstein, T.; Kreutzer, M.; Glocker, M.O. Mass spectrometric peptide analysis of 2DE-separated mouse spinal cord and rat hippocampus proteins suggests an NGXG motif of importance for in vivo deamidation. Electrophoresis 2013, 34, 1610-1618. [CrossRef]

55. Robinson, N.E.; Robinson, M.L.; Schulze, E.S.; Lai, B.T.; Gray, H.B. Deamidation of alpha-synuclein. Protein Sci. 2009, 18, 1766-1773. [CrossRef]

56. Bastrup, J.; Kastaniegaard, K.; Asuni, A.A.; Volbracht, C.; Stensballe, A. Proteomic and Unbiased Post-Translational Modification Profiling of Amyloid Plaques and Surrounding Tissue in a Transgenic Mouse Model of Alzheimer's Disease. J. Alzheimer's Dis. 2020, 73, 393-411. [CrossRef]

57. Sadakane, Y.; Kawahara, M. Implications of Metal Binding and Asparagine Deamidation for Amyloid Formation. Int. J. Mol. Sci. 2018, 19, 2449. [CrossRef]

58. Shimizu, T.; Watanabe, A.; Ogawara, M.; Mori, H.; Shirasawa, T. Isoaspartate formation and neurodegeneration in Alzheimer's disease. Arch. Biochem. Biophys. 2000, 381, 225-234. [CrossRef]

59. Ayers, J.I.; Fromholt, S.E.; O'Neal, V.O.; Diamond, J.H.; Borchelt, D.R. Prion-like propagation of mutant SOD1 misfolding and motor neuron disease spread along neuroanatomical pathways. Acta Neuropathol. 2016, 131, 103-114. [CrossRef]

60. Perez-Riverol, Y.; Csordas, A.; Bai, J.; Bernal-Llinares, M.; Hewapathirana, S.; Kundu, D.J.; Inuganti, A.; Griss, J.; Mayer, G.; Eisenacher, M.; et al. The PRIDE database and related tools and resources in 2019: Improving support for quantification data. Nucleic Acids Res. 2019, 47, D442-D450. [CrossRef]

Publisher's Note: MDPI stays neutral with regard to jurisdictional claims in published maps and institutional affiliations.

(C) 2020 by the authors. Licensee MDPI, Basel, Switzerland. This article is an open access article distributed under the terms and conditions of the Creative Commons Attribution (CC BY) license (http://creativecommons.org/licenses/by/4.0/). 